\title{
La promoción y desarrollo de modelos asociativos de gestión en el Sistema Nacional de Vivienda Colombiano
}

\author{
José Leonardo Guio Espitia \\ Abogado por la Universidad Santo Tomás Tunja, Colombia. Magister en Derecho Público, docente Universidad Santo \\ Tomás Seccional Tunja. Miembro de la Linea de Investigación de Estudios de Derecho Constitucional y Separación de \\ Poderes de la Universidad Santo Tomás Bucaramanga y Bogotá. Correo electrónico: leoguio@gmail.com
}

\begin{abstract}
Resumen
En el presente artículo se aborda el estudio de los Modelos Asociativos de Producción de Vivienda en el marco de los distintos tipos de política pública que han tenido lugar en Colombia desde la segunda mitad del siglo XX; enfatizando el análisis en determinar si el actual Sistema Nacional de Vivienda, previsto en la Ley 3 de 1991, responde adecuadamente al deber constitucional de: "promover formas asociativas de ejecución de programas de vivienda" que prevé el artículo 51 de la Carta Política Colombiana. Desde una perspectiva histórica se analizan los aspectos generales de la Política Higienista de la década del treinta; de la Política Intervencionista e Institucionalización de la Acción del Estado propia de las décadas del cuarenta, cincuenta y sesenta; del tránsito hacia el modelo de las corporaciones de ahorro y vivienda en los años setenta y de la apertura al modelo de desarrollo de mercado en la política de Vivienda de Interés Social en la que incursiona Colombia desde la década del noventa; lo anterior al observar la trayectoria que los modelos asociativos de vivienda han tenido en cada una de las mencionadas etapas.
\end{abstract}

Palabras clave: Política, derecho, vivienda, organizaciones populares de vivienda.

\begin{abstract}
This paper deals with the study of Associative Models of Housing Production in the context of different types of public policy that have taken place in Colombia since the second half of the twentieth century, emphasizing the analysis to determine whether the current National housing, under the Act 3 of 1991, responds appropriately to constitutional duty "to promote associative forms of housing program implementation" provided for in Article 51 of the Colombian Constitution.

From a historical perspective discusses general aspects of the decade Hygienist Policy 30; Interventional Policy and Institutionalization of State Action own the 40,50 and 60, the transition to the model of Corporations Savings and Housing in the 70's and opening the market model of development in the politics of social interest housing ventures in which Colombia since the 90 's, the above path watching the housing associative models have been in each of said steps.
\end{abstract}

Keywords: Politics, law, housing, housing popular organizations.

\begin{abstract}
Résumé
Dans cet article, l'étude des modèles de production associatifs du logement sous différents types de politiques publiques qui ont eu lieu en Colombie depuis la seconde moitié du XXe siècle est discutée; soulignant l'analyse visant à déterminer si le système actuel de logement national, prévu par la loi 3 de 1991, reflète adéquatement le devoir constitutionnel de «promouvoir des formes associatives de la mise en œuvre des programmes de logement" prévues à l'article 51 de la Constitution colombienne. Dans une perspective historique les aspects généraux de la trentaine hygiéniste politique sont analysés; Interventionnelle et de l'action politique Institutionnalisation propre État des années quarante, cinquante et soixante; la transition vers le modèle de la sociétés d'épargne et de logement dans les années soixante-dix et l'ouverture du modèle de développement du marché dans la politique de logement social dans lequel pénètre Colombie depuis les années nonante; l'observation de la associatif modèles de chemin d'accès ci-dessus présente un logement dans chacune desdites étapes.
\end{abstract}

Mots-clés: Politique, droit, bricolage, organisations populaires, bricolage.

Recibido: 24 de junio de 2014, Aprobado: 30 de septiembre de 2014. 



\section{La promoción y desarrollo de modelos asociativos de gestión en el Sistema Nacional de Vivienda Colombiano*}

José Leonardo Guio Espitia

\section{INTRODUCCIÓN}

En el presente artículo se indaga si el actual Sistema Nacional de Vivienda (SNV) estatuido, principalmente, mediante la Ley 3 de 1991 y la Ley 1537 del 2012, desarrolla de manera adecuada el mandato constitucional previsto en el Artículo 51 de la Constitución Política, que establece la formulación de una Política Pública de Vivienda a partir de la promoción de Modelos Asociativos de Gestión de Vivienda Prioritaria que coadyuven al sistema de financiación formal y complementen el desarrollo de programas de vivienda de interés social de iniciativa estatal. En efecto, el citado artículo establece: "Todos los colombianos tienen derecho a vivienda digna. El Estado fijará las condiciones necesarias para hacer efectivo este derecho y promoverá planes de vivienda de interés social, sistemas adecuados de financiación a largo plazo y formas asociativas de ejecución de estos programas de vivienda"; estando así, por disposición del constituyente primario se erige la formulación, implementación y evaluación de la política pública de Vivienda de Interés Social Colombiana (VIS) en tres estrategias fundamentales: i) en la oferta de proyectos de vivienda de origen Estatal o Privado; ii) en un sistema financiero regulado y de largo plazo de acuerdo con la capacidad de pago del sector asalariado; y iii) en la generación de soluciones V.I.S., derivadas de modelos asociativos o comunitarios de gestión ${ }^{1}$, siendo este último instrumento de política pública el eje y objeto del presente artículo.

\footnotetext{
* El presente texto es producto de la investigación: "Las organizaciones populares de vivienda en Boyacá". Convenio 764 Colciencias. Grupo de Investigación, Temas de Arquitectura. Línea, Habitat Popular y Desarrollo Urbano Regional. Universidad Santo Tomás Tunja, Boyacá.

1 Se entiende por Modelos Asociativos de Gestión de Vivienda el desarrollo de acciones colectivas objetivas formalizadas en personas jurídicas sin ánimo de lucro, enmarcadas en lo que el Decreto 2391 de 1989 ha denominado Organizaciones Populares de Vivienda OPVs, las cuales tienen por objeto social el desarrollo de programas de vivienda para sus afiliados por medio del sistema de autogestión o participación comunitaria para su construcción.
} 
En este orden de ideas, cabe preguntarse si en el diseño de los mecanismos, estrategias, instrumentos y decisiones que dan carácter a nuestra política pública es fomentada, en forma efectiva, la autogestión comunitaria de vivienda como instrumento de política pública de alcance constitucional, y de una profunda connotación dogmática para nuestro Estado social de derecho fundado en el principio de la solidaridad; para tal propósito, se acudirá a una metodología analítica descriptiva que pasa por una revisión general de los antecedentes históricos en materia de política de vivienda, para luego revisar las notas características de la política actual y evaluar su impacto en la promoción de las "Organizaciones Populares de Vivienda (OPV)" como expresión de los modelos asociativos de gestión de vivienda.

\section{BREVE RESEÑA HISTÓRICA DE LA POLÍTICA NACIONAL DE VIVIENDA EN COLOMBIA}

Es fundamental partir de una perspectiva histórica que sirva de referente y contribuya a la conceptualización que de la problemática de la vivienda se concibió en el seno del Estado de derecho colombiano del siglo XX, y que dio lugar al carácter que orientó la inversión y enfocó la regulación e intervención estatal en cada época significativa de ese siglo, acuñando así un particular diseño institucional en las sucesivas etapas de la Política de Vivienda, desde donde se promovió la accesibilidad a un bien de tan alto valor social y político, como lo es, sin duda, la vivienda.

No obstante, es posible estudiar esquemas de intervención estatal desde el periodo comprendido entre 1918 y 1942; en lo que se ha descrito como el inicio de la acción estatal con énfasis en el higienismo; para los fines del presente artículo acotaremos esta revisión histórica al análisis general de los periodos denominados: "La institucionalización de la acción estatal frente al problema de la vivienda (1942-1965), al periodo de la transición en el manejo institucional del problema de la vivienda (1965-1972), y a la etapa de la creación de las corporaciones de ahorro y vivienda (CAV)" ${ }^{\prime 2}$, como antesala a lo que es hoy en día el Sistema Nacional de Vivienda incorporado con la Ley 3 de 1991.

Con el estudio histórico introductorio que se desarrollará a continuación se busca dar cuenta de cómo se transita de la estatalización de la política en las décadas del cincuenta al ochenta hacia la liberalización e introducción al modelo de la economía de mercado en materia de vivienda, a partir de la década del noventa con la consecuente reducción del papel del Estado en la producción directa de vivienda de interés social, y su relegación general al rol de regulador y cofinanciador en el sector; así se dio paso de un modelo de política intervencionista a la política del subsidio familiar de vivienda, como incentivo a la demanda en el mercado de la vivienda de interés social.

2 Para el análisis histórico que se propone en el presente artículo nos basaremos en el estudio realizado por Ceballos, Saldarriaga y Tarchópulos (2008). 


\section{Periodo higienista (1918-1942) ${ }^{3}$}

Es importante resaltar que el Modelo Administrativo de esta fase de la política estatal se centró en conjurar las precarias condiciones de habitabilidad e higiene que acompañaron el fenómeno desaforado de urbanización, desencadenado por el proceso de industrialización económica que vivió el país en la época, y que se tradujo en el riesgo latente de una emergencia sanitaria en los barrios populares y obreros de las grandes ciudades a causa de la ausencia total o a la deficiente prestación de los servicios públicos domiciliarios básicos, principalmente en las zonas perimetrales en proceso de densificación por la ola de migrantes rurales que se asentaron en las principales ciudades del país. Asimismo, la precaria red de hospitales públicos y atención médica, la inexistente o insuficiente prestación del servicio público de transporte, la ausencia de equipamientos urbanísticos, viales y de esparcimientos básicos y el hacinamiento de familias numerosas en unidades de vivienda sin condiciones mínimas de salubridad y habitabilidad, confluían y conspiraban en contra de los epicentros urbanos del desarrollo industrializado de comienzos de siglo (Santana, 1982) ${ }^{4}$.

La retracción de la economía mundial debido a la ruina que produjo la Gran Guerra Europea y la gran crisis financiera de 1929 en Estados Unidos e Inglaterra, incidió en el desarrollo de la base industrial requerida para satisfacer la demanda interna y sustituir la dependencia en las importaciones de bienes e insumos del exterior que escaseaban; igualmente, el auge en las exportaciones de oro, café y algodón implicaron importantes inversiones en infraestructura para su recolección, transporte y procesamiento, demandando ello la ampliación gradual de la base obrera, que terminó asentándose en las principales ciudades para incorporarse en la industria y llevar a cabo un proyecto de vida citadino (Tirado, 1998; Ospina, 1955). Este auge en la industrialización de los años veinte se acompañó de un ambiente político centralista e intervencionista, inspirado en la necesidad de convalecerse de la desintegración territorial, y de recuperar el tiempo perdido en la Guerra de los Mil Días, dando así paso a la estatalización de los principales aspectos de la sociedad, al intervencionismo económico, al centralismo político y administrativo del Estado en cabeza del Presidente, lo cual permeó y caracterizó el papel del Estado en la formulación de la política de vivienda.

En este escenario se proyecta una política enmarcada en el concepto de la vivienda como un asunto de salud pública, la cual trasciende el discurso demagógico de los políticos liberales y conservadores, que prometen reivindicar a las hacinadas

3 Clasificación histórica descrita por Ceballos, Saldarriaga y Tarchópulos (2008, pp. 51 - 167).

4 Evidencia un crecimiento en la población urbana inversamente proporcional al descenso en la población rural para el periodo comprendido entre 1938 y 1973, que pasa por un censo urbano de 30.9 miles en 1938 a 63.6 miles de habitantes en las principales ciudades del país para el año de 1973. 
y maltrechas masas proletarias de la época, centrando la actividad legislativa en la expedición de códigos sanitarios, en la creación del primer cuadro institucional para el sector, entre otras medidas legislativas que se relacionan a continuación:

Tabla 1. Normatividad periodo higienista

\begin{tabular}{cc} 
NORMA & OBJETO \\
\hline Ley 46 de 1918 & $\begin{array}{c}\text { Por medio de la cual se dicta una medida de salubridad pública y } \\
\text { se provee a la existencia de habitaciones higiénicas para la clase } \\
\text { proletaria. }\end{array}$ \\
\hline Ley 68 de 1924 & $\begin{array}{c}\text { Creación del Banco Agrícola Hipotecario, entidad que se encargó de } \\
\text { atender la problemática de la vivienda rural. }\end{array}$ \\
\hline Ley 70 de 1931 & $\begin{array}{c}\text { Se establecieron garantías jurídicas para el patrimonio de familia, } \\
\text { mediante la in-embargabilidad de la vivienda familiar. }\end{array}$ \\
\hline Decreto 306 de 1940 & $\begin{array}{c}\text { Creó la Liga Nacional de Vivienda Rural como instancia encargada } \\
\text { de fomentar el mejoramiento de las condiciones higiénicas de la } \\
\text { vivienda rural. }\end{array}$ \\
\hline $\begin{array}{c}\text { Mediante su expedición se sentaron las bases para la fundación del } \\
\text { Banco Central Hipotecario (BCH), que en el futuro sería un actor } \\
\text { institucional crucial para reducir el déficit cuantitativo de vivienda en } \\
\text { las décadas de los años cuarenta, cincuenta y sesenta. }\end{array}$ \\
\hline $\begin{array}{c}\text { Se plantean los primeros esquemas de descentralización de la } \\
\text { política higienista de vivienda, mediante la competencia otorgada a } \\
\text { los municipios para la construcción de Barrios Populares Modelos } \\
\text { supervisados por el Nivel Central. }\end{array}$ \\
\hline
\end{tabular}

Fuente: Elaboración propia del autor. Convenio 746 Universidad Santo Tomás Seccional TUNJA - Colciencias

Asimismo, en este periodo tuvo lugar la misión financiera liderada por Edwin Walter Kemmerer, que trascendió en importantes transformaciones al modelo administrativo del Estado, incorporando el concepto de la Banca Pública, la Regulación macroeconómica y microeconómica del mercado nacional y las primeras concepciones de la planificación para el desarrollo social. En este periodo se plantearon audaces políticas de reforma agraria con fundamento en el principio constitucional de la utilidad social de la propiedad previsto en la Constitución de 1886 que, pese a no ser materializadas, deben ser registradas honrando a presidentes como Alfonso López Pumarejo (1934-1938); igualmente, se sentaron las bases de lo que en el futuro sería el Instituto de Crédito Territorial (ICT), que junto con el Banco Central Hipotecario $(\mathrm{BCH})$ serían actores de primer orden en este periodo y en los sucesivos modelos de política hasta su declive y desaparición en la década del noventa. 
Como se ha mencionado, en este periodo tiene lugar la conceptualización de la problemática de la vivienda como un asunto de salud pública de interés estratégico para el Estado, generando embrionarios esquemas de regulación del sector, y el establecimiento de un primer cuadro institucional de carácter intervencionista representado en el naciente Banco Agrícola Hipotecario, el Instituto de Crédito Territorial y en el rol desempeñado por el Banco Central Hipotecario. En este sentido y atendiendo a que en estas entidades recaía buena parte del desarrollo de la política en el periodo Higienista, es fundamental analizar su marco misional y funcional tanto para conocer su alcance, como para evidenciar el calado de las transformaciones de las que, en periodos futuros, fueron objeto estas instituciones:

El rol del Banco Central Hipotecario (BCH): mediante la Ley 170 de 1936 se deja en cabeza del $\mathrm{BCH}$ la implementación de una estrategia financiera que promueva programas de urbanización y construcción - tanto urbanos como rurales-, focalizados principalmente en atender a la población obrera del país, al respecto refiere la citada norma: "Artículo 1: Autorícese al $\mathrm{BCH}$ para suscribir un millón de pesos en acciones de una compañía subsidiaria, que colabore con él en la adquisición de terrenos para casas y granjas familiares destinadas a empleados y obreros, y en la edificación y acondicionamiento de ellas.” De igual forma, el Banco podría financiar vivienda urbana y granjas familiares para empleados y obreros hasta por el $75 \%$ del valor de estas, haciendo presencia el Banco en aquellas ciudades con más de ochenta mil habitantes.

Creación del Instituto de Crédito Territorial (ICT): mediante el Decreto 200 de 1939, en el Gobierno del Presidente Eduardo Santos Montejo (19381942), es creado el ICT como una entidad adscrita a los entonces llamados Bancos de Crédito Territorial, la cual se caracterizó por ser una entidad descentralizada funcional y territorialmente en el país, con patrimonio autónomo, y cuya función principal fue otorgar préstamos destinados a financiar vivienda campesina principalmente. Dentro de las funciones asignadas se destaca por novedosa la facultad de importación de materiales para la construcción de viviendas campesinas con cero arancel y las tasas de interés subsidiadas, que mediante préstamos de hasta de 30 años podrían ser del 3\% efectivo anual. Para el año 1943, mediante el decreto 1579, se amplió el rango de acción del ICT, facultándolo para intervenir la oferta de vivienda urbana mediante la creación de la Sección de Vivienda Urbana, encargada de otorgar créditos a municipios, créditos directos a obreros y empleados, construir barrios populares por su propia cuenta, y prestar apoyo técnico a municipios para la construcción de barrios populares en áreas urbanas principalmente.

El rol del Banco Agrícola Hipotecario: con la creación de este Banco el Gobierno buscó incentivar el ahorro individual necesario para el otorgamiento de créditos destinados a vivienda, a través de la colocación 
en el mercado de cédulas hipotecarias emitidas por el Banco, exentas de impuestos y gravámenes; de igual forma, se esperaba que con la transacción producto de la venta de las cédulas el banco capitalizara recursos para impulsar proyectos de vivienda en el sector rural y urbano.

Figura 1. Modelo Administrativo Organizacional Centralizado

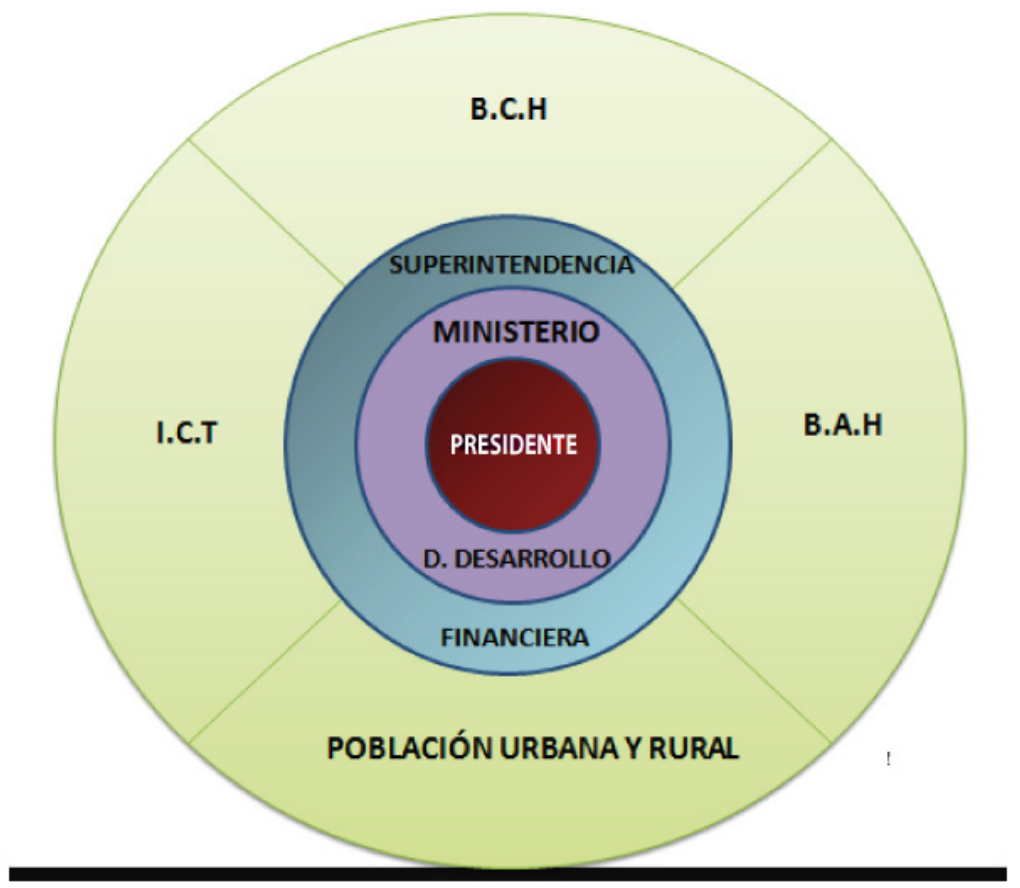

Fuente: elaboración propia - Convenio No. 764 Colciencias - Universidad Santo Tomás Seccional TUNJA.

Para la década de los cuarenta se advierte en este modelo de política una concepción institucionalista centralizada del papel intervencionista del Estado frente a las novedosas, crecientes, pero típicas problemáticas de una sociedad que en pleno desarrollo industrial empezaba a gravitar alrededor de las ciudades-epicentro de la economía nacional, dando ello lugar a la conformación de grupos poblacionales bien caracterizados y con expectativas de su inclusión política, social, económica y urbana a la ciudad, siendo esto posible solo mediante la debida prestación de servicios públicos domiciliarios, de transporte, de educación, de salud y, por supuesto, de vivienda adecuada, y recayendo esta responsabilidad en el Estado y sus instituciones. En este contexto es claro que en el periodo "higienista" surge un primer andamiaje institucional público conformado por entidades bancarias e institutos encargados 
de implementar instrumentos financieros, administrativos y de captación de recursos enfocados a la ejecución directa de proyectos de viviendas populares, a su mejoramiento y acondicionamiento de acuerdo con las condiciones de salubridad para ese entonces codificadas-. Asimismo, a otorgar créditos a largo plazo con tasas de interés subsidiadas en busca de fomentar el ahorro para la adquisición de vivienda por la clase obrera y empleada, y a suministrar materiales para la autoconstrucción y el mejoramiento de la vivienda urbana o rural por parte de sus propietarios.

\section{Los modelos asociativos de gestión de vivienda en el periodo higienista}

Incentivados por las iniciativas gubernamentales higienistas y agobiados por la precariedad del marginalismo afloraron en la época modelos asociativos de gestión de vivienda basados en el cooperativismo proletario y asalariado, que constituyeron un modelo alternativo de economía solidaria audaz y efectivo para acceder a las condiciones mínimas, que imponían la vida moderna y la lógica del hábitat en una sociedad industrializada.

Fueron múltiples los proyectos de vivienda de carácter social que se concretaron mediante el modelo cooperativo en el periodo comprendido entre 1934 y 1945 en las ciudades de Medellín, Cali, Santa Marta y Bogotá, cobrando dicho modelo de autogestión de vivienda tal relevante que en 1945 se llevó a cabo el Primer Congreso Nacional de Cooperativas de Colombia con sede en la ciudad de Medellín (Rodríguez, 2006).

Las iniciativas de autogestión surgidas en el cooperativismo de este periodo se materializaron en varios proyectos de vivienda que podríamos considerar emblemáticos, y cabe mencionar: i) el Barrio del Empleado construido en Medellín en 1934 por la Cooperativa de Empleados de Antioquia; ii) el barrio Los Laureles de Medellín, en el que la Cooperativa de Habitaciones construyó 292 casas; iii) el conjunto habitacional Las Acacias en Medellín, construido por la Cooperativa de Institutores conformada por el magisterio antioqueño; lo propio ocurrió en Cali, Santa Marta y Bogotá, entre otros. (Rodríguez, 2006).

\section{Modelo de política de vivienda caracterizado por la institucionalización de la acción estatal (1942 y 1965) (Ceballos, 2008)}

Este modelo es desarrollado teniendo como telón de fondo el fenómeno generalizado de violencia partidista entre el año 1949 y 1965, desencadenado por el asesinato del caudillo liberal Jorge Eliécer Gaitán en el año 1948, el golpe de Estado y el gobierno militar del general Rojas Pinilla entre los años 1953 y 1957, y el establecimiento del Frente Nacional como acuerdo político para la recuperación de la gobernabilidad del Estado durante el periodo comprendido entre 1958 y 1974.

La sociedad colombiana de la época transitaba del modelo sociológico y económico -netamente agrario- al modelo semi-industrializado basado en la producción de bienes en masa, cada vez más tecnificados gracias a los adelantos científicos propios 
de esta transición, los cuales repercutieron en el mejoramiento de la calidad de vida de la población que experimentó importantes fenómenos positivos como el de la "explosión demográfica" o de "natalidad" -evidenciada en las drásticas reducciones de la mortalidad infantil-, generando un aumento poblacional de 12 millones para 1950, a 40 millones para el final del siglo $\mathrm{XX}^{5}$. Igualmente, se reportaron avances estructurales en el control epidemiológico de enfermedades infecciosas y parasitarias que atacaban a la población adulta, reduciendo su capacidad productiva; ambiente de bienestar que es explicable, entre otras causas, a partir del agresivo intervencionismo de las políticas estatales higienistas, de salubridad, de vivienda, en servicios públicos, educación y salud en general (Gaviria, 2010). No obstante lo anterior, era inevitable que el tránsito al modelo de desarrollo industrializado de manera simultánea surtiera efectos nocivos en términos de la alta concentración poblacional que este demandaba, la incapacidad de redistribuir los ingresos en porcentajes suficientes para mejorar la calidad de vida de la clase obrera, la aparición de un precario régimen de seguridad laboral, industrial y social, la contaminación ambiental y el desinterés de la clase industrial por articularse con el Estado para ofrecer un modelo de desarrollo sostenible en términos ambientales, económicos, sociales y humanos.

En esta etapa de desarrollo de la política se observa la importancia que toma la problemática de la vivienda en los discursos presidenciales de la época, en los que se enfatizaba el liderazgo del orden nacional en el diseño e implementación de estrategias encaminadas a promover de forma decidida la construcción masiva de vivienda como una cuestión de justicia social, e incluso de calamidad pública de alto interés estatal, lo anterior dio paso a que desde la agenda política nacional se desarrollara un proceso de fortalecimiento y maduración del andamiaje institucional encargado de dinamizar la oferta de vivienda en procura de reducir el déficit cuantitativo urbano y rural, en un claro ejercicio de intervencionismo estatal en el sector.

En este contexto, se expiden las leyes y decretos ${ }^{6}$ reglamentarios tendientes a delimitar competencias y funciones, a ampliar el alcance de intervención y a fortalecer financiera y administrativamente entidades como el Instituto de Crédito

5 Explosión demográfica que tuvo un descenso importante con la entrada de los métodos anticonceptivos y producto de la ampliación de la cobertura en educación, que permitió reducir la tasa de natalidad de 7 hijos en promedio por núcleo familiar de 1965, a un promedio de tres hijos por núcleo familiar para el 2005, según cifras del DANE.

6 Ley 1 de 1943: Por la cual se otorgan facultades a los municipios para la declaratoria de utilidad pública de inmuebles baldíos destinados a vivienda de interés social; Decreto 53 de 1942: Por el medio del cual se reglamentaron los préstamos a las Cooperativas de Habitaciones; Decreto 1575 de 1946: "Por medio del cual se autorizan los planes de financiamiento de viviendas para trabajadores, con pignoración de salarios, cesantías y seguros de vida; Ley 85 de 1946: por medio de la cual se provee a la financiación de viviendas para trabajadores a través de las empresas empleadoras, se crean las Juntas Departamentales de Vivienda y se le otorgan facultades para la reglamentación técnica en la construcción de viviendas al ICT; Ley 87 de 1947: por medio de la cual se crea la Caja de Vivienda Popular; Decreto 1371: Por medio del cual se crea el Código Sanitario Nacional; Decreto 2462 de 1954: Por medio del cual se establece el subsidio familiar de Vivienda a cargo del ICT; Decreto 2349 de 1965: Por medio del cual se crea el Banco de Ahorro y Vivienda, entre otras normas enfocadas al fortalecimiento del sector de la construcción de vivienda y del cuadro institucional desarrollador de la política. 
Territorial (ICT), el Banco Central Hipotecario $(\mathrm{BCH})$ y la Caja de Crédito Agrario Industrial y Minero ${ }^{7}$. Asimismo, fueron creadas otras entidades y organismos de gran importancia como la Caja de Vivienda Militar, las Juntas Departamentales de Vivienda, el Instituto Colombiano de Colonización e Inmigración, y el Banco de Ahorro y Vivienda, entre otras; en sí la actividad legislativa y gubernamental se tradujo en un proceso de ajuste y fortalecimiento institucional, que se podría graficar de la siguiente manera:

Figura 2. Modelo Administrativo y Organizacional del Periodo de la Institucionalización

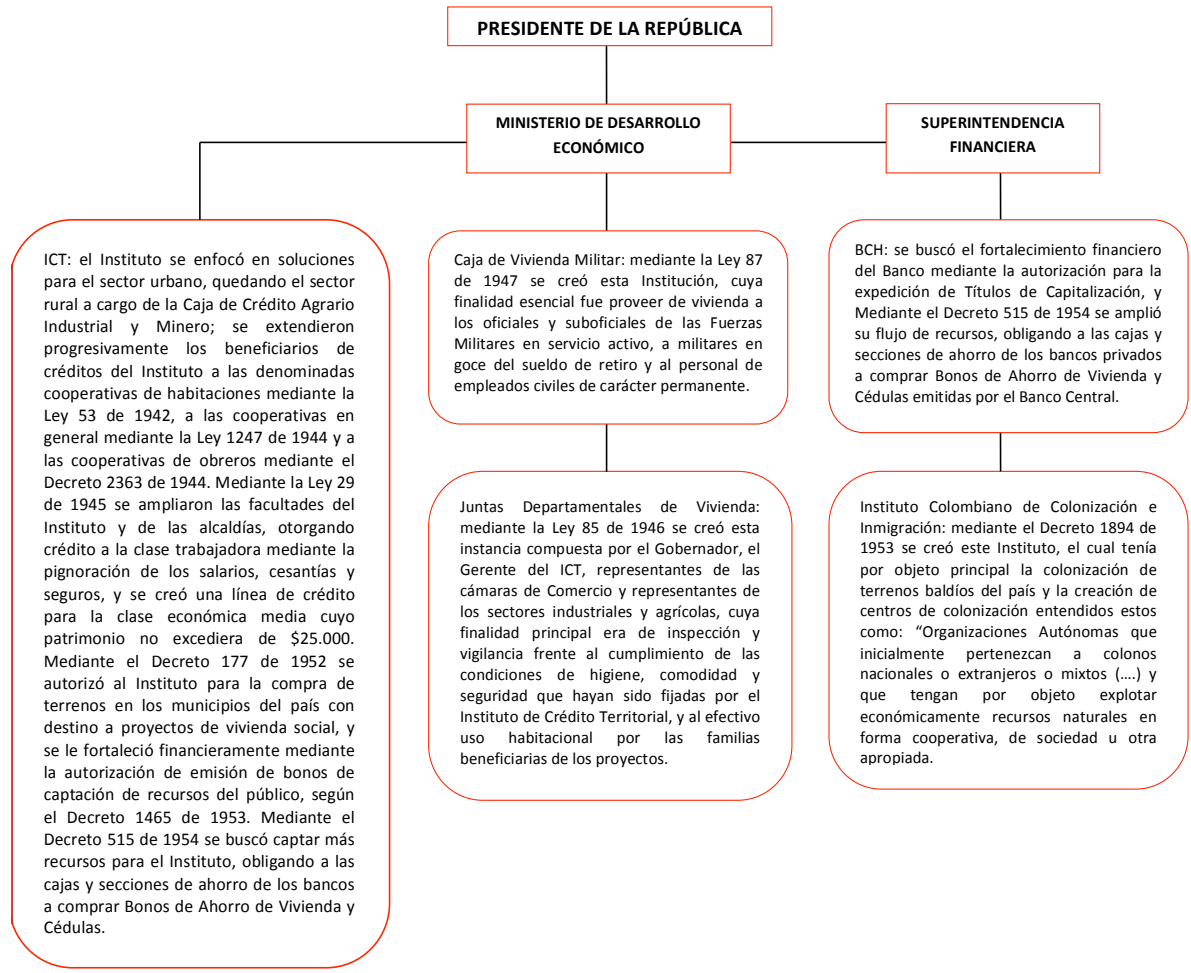

Fuente: elaboración propia.

Dentro de las estrategias de intervención y regulación del sector, en este periodo se debe destacar la expedición del Decreto 1371 de 1953, con el cual se adoptó el Código Nacional Sanitario que incluía parámetros básicos para urbanizaciones y vivienda, y se reglamentó su autorización; de igual forma, se canalizaron esfuerzos

7 Para conocer algunas cifras sobre el aumento progresivo en el número de viviendas construidas por intervención directa del ICT, BCH y Banco Agrario Industrial y Minero, se recomienda ver Urrutia y Namen (2011). 
y recursos institucionales para fomentar las sociedades mutualistas de ahorro y préstamo, fomentar el ahorro popular con destino a la construcción de proyectos de vivienda y ampliar la inversión del sector privado en la solución de esta problemática. Asimismo, se desarrollaron planes como la Alianza para el Progreso, planes de intervención urbanística y de ampliación de servicios públicos en barrios subnormales, inversión en infraestructura para fomentar la valorización del suelo urbano y se instrumentalizó la declaración de utilidad pública de inmuebles baldíos con destino a desarrollos habitacionales para estratos populares (Ceballos, 2008).

Dada la consolidación de una clase asalariada en expansión, además del fortalecimiento institucional expuesto, buena parte de los instrumentos económicos y financieros de la política de vivienda de este periodo se desarrollaron a propósito de la legislación laboral, que se encargó de promover la capacidad de ahorro en los trabajadores con destino a lograr la cuota inicial para la adquisición de vivienda. Es así como, mediante la Ley 6 de 1945, fueron creadas las cesantías en calidad de un auxilio a razón de un salario por año de trabajo -a cargo de los empleadores-; igualmente, se crean entidades misionalmente dedicadas a ofrecer condiciones de seguridad social para este sector de la población como las Cajas de Previsión, el Sistema de Subsidio Familiar, el Instituto de Seguro Social, el Servicio Nacional de Aprendizaje (SENA), que de forma directa o indirecta ofrecían condiciones laborales que incidían en mejores posibilidades para la adquisición de vivienda de la clase trabajadora formal, instituciones que terminaron por constituir escenarios propicios para la conformación de modelos asociativos de vivienda de carácter obrero y gremial; asimismo, los modelos administrativos, financieros y misionales del sistema de seguridad social inspiraron la conformación de organizaciones, asociaciones o corporaciones gremiales o profesionales encargadas de mejorar las condiciones de vida de la clase trabajadora y, por supuesto, de la provisión de vivienda popular.

\section{Los modelos asociativos de gestión de vivienda en el periodo de la institucionalización}

En similares lógicas de maduración y fortalecimiento a las evidenciadas en la institucionalidad estatal se inscribió el Movimiento Asociativo de la época, aflorando así multiplicidad de modelos cooperativos de gestión de vivienda de interés social con caracteres cada vez mejor definidos y especializados, de los cuales podemos referenciar algunas tipologías de asociación, de acuerdo con el estudio realizado en 1965 por la Oficina Internacional del Trabajo:

Cooperativas de Urbanización: en ellas la forma asociativa adquiere el terreno, realiza el proyecto y las obras de urbanización, adjudicando luego lotes a los asociados, que posteriormente pueden ser construidos por cuenta propia o colectivamente, pero la propiedad de la vivienda es individual. 
Cooperativas de Edificación o Construcción de Vivienda: el proceso de construcción se desarrolla en forma cooperativa hasta llegar a la titulación individual de la vivienda.

Cooperativas de Trabajadores de la Construcción: similar a la anterior, los trabadores se unen para tal efecto y pueden contratar diferentes obras para otro tipo de organizaciones o usuarios.

Cooperativas de Habitación o de Propiedad Colectiva: es la verdadera 'Cooperativa de Vivienda', en la cual la Cooperativa conserva la propiedad de los inmuebles, el socio o asociado paga su vivienda dentro del plan de financiamiento respectivo y adquiere un derecho como copropietario o usufructuario en las condiciones preestablecidas. En otros términos, los asociados no son dueños individuales sino propietarios indirectos, puesto que su condición de asociados los constituye en propietarios de la cooperativa (Álvarez, 2006, p. 18).

Estos modelos cooperativos de gestión de vivienda se inspiraron en los principios de la economía solidaria, encaminándose a la generación de capital social mediante la disposición de recursos materiales e inmateriales en un modelo ético comunitario fundado en la reciprocidad y la solidaridad para el mejoramiento de sus condiciones materiales de vida. Es así como, además de las cooperativas de gestión de vivienda de carácter gremial como las enunciadas, florecieron otros modelos como las corporaciones mutualistas de ahorro y crédito, las corporaciones y fundaciones de bienestar social para trabajadores, cooperativas de profesionales, entre otras, que convirtieron este periodo en un hito importante en materia de autogestión de vivienda, dando ello lugar a que desde el Programa de Gobierno del presidente Guillermo León Valencia (1962-1966), al margen de la construcción directa de vivienda liderada por el $\mathrm{BCH}$ y el ICT se promovieran estrategias para fomentar la autoconstrucción, "permitiéndole a las familias recibir supervisión técnica para la construcción de su vivienda, crédito a largo plazo para la compra de materiales y crédito para la compra del lote en zonas de vivienda obrera [...] Este programa era auspiciado y apoyado por la agencia de Cooperación para el desarrollo del gobierno de los Estados Unidos (AID)" (Ceballos, 2008, p. 102).

\section{Periodo de la transición en el manejo institucional del problema de la vivienda (1965-1972) (Ceballos, 2008)}

Esta etapa de transición está marcada por un proceso de modernización de la Administración Pública colombiana expresada en la incorporación de instrumentos macros de planificación en los planes nacionales de desarrollo, a partir de los cuales se buscó la racionalización de los recursos económicos, administrativos, políticos 
e institucionales en pro de la atención integral a problemáticas como la salud, la educación, el empleo y la vivienda, abordados a través de esquemas de coordinación institucional en procura de ganar eficacia y eficiencia en el actuar estatal.

Es importante resaltar una ampliación importante en la conceptualización de la problemática de la vivienda sorteada en este periodo con la incorporación que el discurso de la política nacional hizo del déficit cualitativo de vivienda, en la necesidad de articular la planificación urbana a la comprensión del problema, viéndolo así desde una concepción más integral.

Las líneas generales de acción del Estado se centraron en: i) Controlar los costos de la tierra urbanizable ; ii) la canalización de recursos para promover la vivienda social y el fortalecimiento del cuadro institucional que desarrollaba la política nacional mediante la construcción de barrios y viviendas populares, que a cargo de ICT presentó un repunte significativo9; iii) estrategias para empezar a fomentar la participación del sector privado de la construcción en programas de vivienda de interés social ${ }^{10}$; iv) el impulso dado al sector de la vivienda social desde el Programa Alianza para el Progreso, que redundó en el fortalecimiento del sistema de gestión de vivienda mediante la autoconstrucción, como el adelantado en el barrio Kennedy de Bogotá; v) la regulación de la oferta de la vivienda para combatir la informalidad y el riesgo de fraude a los ahorradores con la expedición del Decreto 979 de 1966; vi) la reglamentación de las condiciones de crédito de las asociaciones mutualistas de ahorro y vivienda, y de las cajas y secciones de ahorro de los bancos ${ }^{11}$; vi) la concientización de la importancia de la planificación urbana en el marco de la política

$8 \quad$ El presidente Misael Pastrana Borrero (1970-1974) en su Plan Nacional de Desarrollo "Las Cuatro Estrategias" estableció como una de ellas el énfasis en el desarrollo urbano, en tanto instrumento dinamizador de la economía, al vincular el capital privado a la producción de los insumos y materiales necesarios para los proyectos de expansión urbana, y mejorar así la demanda interna de bienes y servicios e incrementar el empleo de mano de obra no calificada; dentro de la estrategia del desarrollo urbano se reconoció como un obstáculo la especulación en el mercado del suelo, el cual fomentaba la concentración de la riqueza y dificultaba la redistribución del ingreso y la riqueza que, de hecho, constituía otra de las estrategias principales de su Plan de Desarrollo.

9 "La urbanización aumentó aceleradamente en la primera parte del período de análisis. Entre los años censales (1951 y 1964), el grado de urbanización pasó de 39\% a 52\%, un aumento equivalente a una tasa anual de 26 por mil" (Gaviria, 2010).

10 Dentro de la primera Misión Oficial del Banco Mundial que tuvo lugar en 1949 y fue liderada por el economista canadiense Lauchlin Currie -denominada "Operación Colombia"-, se plantearon una serie de medidas para el sector de la vivienda encaminadas a generar estímulos a la inversión privada, siendo estas recomendaciones paulatinamente incorporadas a la legislación colombiana y al diseño administrativo del Estado; dentro de estas queremos destacar: centralizar en una sola institución hipotecaria los recursos públicos, del ahorro y de inversionistas destinados a vivienda para optimizar su administración e inversión; otorgamiento de préstamos de vivienda hasta por el $90 \%$ del su valor total, amortizados hasta 15 años; los costos de las amortizaciones en los créditos a largo plazo serían asumidos por el gobierno y financiados con los intereses que se cobraban por el préstamo de dinero a la entidad hipotecaria; otorgamiento de créditos hasta del $80 \%$ a corto plazo para constructores desarrolladores de proyectos de vivienda de carácter social; fomentar la construcción mixta de casas y edificios, atendiendo a la necesidad de densificar algunas zonas donde escaseaba el suelo, entre otros.

11 En este periodo fueron expedidos el Decreto 2032 de 1966, reglamentario de las Asociaciones Mutualistas de Ahorro y Préstamo, y el Decreto 2661 de 1966, con el cual se reglamentó la tasa del interés en los créditos concedidos por el ICT. 
de vivienda social, resultado del diagnóstico efectuado por el economista Lauchlin Currier en la Misión del Banco Mundial, denominada "Operación Colombia"; vii) la creación del Fondo Nacional del Ahorro en el año 1968 para fomentar la producción de vivienda en los empleados del sector público, y del Consejo Superior de Vivienda y Desarrollo Urbano, mediante el Decreto 209 de 1969, para fortalecer el sector y la expedición de dos normas que incorporarían un cambio radical, para ser desarrollado en una etapa posterior de la política de vivienda, esto es, la Expedición del Decreto 677 y 678 de 1972, con los cuales se crearon la Junta de Ahorro y Vivienda y el Fondo de Ahorro y Vivienda del Banco de la República, y se autorizó la constitución de las corporaciones de ahorro y vivienda con el objeto de promover el ahorro privado, y canalizarlo hacia la industria de la construcción, lo cual sería el punto de partida para el auge de los esquemas financieros en la producción de vivienda social (Ceballos, 2008).

Ahora bien, en 1965 tuvo lugar la misión de Lauchlin Currie, economista canadiense líder de la Primera Misión del Banco Mundial en Colombia, quien en un extenso estudio recomendó abandonar gradualmente los marcos de política macroeconómica implementados, y el modelo de desarrollo de contención de la población rural implantado en el país por la Alianza para el Progreso, por el Plan Decenal de Desarrollo, la Reforma Agraria y la Asociación Latinoamericana de Libre Comercio (ALLC) y, en cambio, encauzar al país hacia una economía de mercado mediante una inflación controlada, la reducción de la deuda externa, e incentivos para la inversión de capitales en los renglones estructurales de la economía. Respecto del déficit cuantitativo acumulado de vivienda, la Misión recomendó apalancar el sector de la construcción a través de un modelo financiero que resultara atractivo para el sector privado, y que concentrara los recursos públicos del ahorro particular, de seguros y de la banca privada, en una sola entidad hipotecaria especializada en otorgar crédito para vivienda social con tasas de interés ligadas al costo de vida y mediante una larga amortización a ser subsidiada por el sector público, propuesta que sin duda afianzaría el papel de las corporaciones de ahorro y vivienda creadas en este periodo (Ceballos, 2008).

\section{La creación de las corporaciones de ahorro y vivienda entre 1972 y 1990 (Ceballos, 2008)}

Este modelo de política - como se indicó- fue concebido en el periodo de transición con la expedición de los Decretos 677 y 678 de 1972, a partir de los cuales se autorizó la creación de las corporaciones de ahorro y vivienda en el gobierno del presidente Misael Pastrana Borrero (1970-1974); sin embargo, su real y exponencial desarrollo se presentó en el lapso de los 28 años subsiguientes, en el que la dinámica del sector financiero le imprimió todo su carácter economicista y monopólico, enfocando la producción de vivienda a los sectores con flujo de ingresos y efectiva capacidad de pago. 
La inversión de los recursos de la banca privada, concebida como un instrumento estratégico y fundamental en el modelo financiero en el que se edificó la Política de Vivienda Nacional de la época, terminó transformando estructuralmente la lógica del discurso gubernamental, el cuadro de intervención institucional y la focalización de la inversión de los recursos públicos del sector, de cara a un escenario claramente dominado por la dinamización de la oferta de vivienda financiada en los créditos hipotecarios de la banca privada.

Por otra parte, los ahorros del sector de comerciantes independientes, de empleados e incluso de la clase media-alta no cubiertos por la oferta de vivienda pública, fueron invertidos progresivamente en las $\mathrm{CAV}$, que ofertaban créditos para vivienda en el marco de un modelo financiero con tasas de interés controladas por indicadores que reflejaban el costo de vida como la inflación, amortizaciones para el pago del crédito en plazos de diez y quince años, y la posibilidad de recibir y gozar de la vivienda en términos cada vez más razonables por cuenta de eficientes empresas constructoras dotadas de un músculo financiero originado en créditos especiales para construcción, otorgados por las mismas CAV.

La incursión de la banca privada en la financiación del sector de la vivienda es solo explicable a partir de los incentivos e instrumentos desarrollados por el Gobierno para combatir el fenómeno de la corrección monetaria ${ }^{12}$, que en inversiones de capital a largo plazo - como es el caso de los créditos para vivienda a diez y quince años-, acababa por generar la depreciación del capital invertido, al ser esta la principal causa de contracción de la inversión de la banca en el sector. Es así como la 'Unidad de Poder Adquisitivo Constante' (UPAC) se convirtió en el instrumento estructurante para lograr la confluencia de los recursos del capital financiero y el de los ahorradores, que observaban en su efecto de indexación constante del capital invertido una oportunidad única para encaminarse hacia la adquisición de una vivienda, por medio del ahorro y del sistema del crédito financiero ofertado por las CAV (Urrutia y Namen, 2011).

No obstante, se advertían algunos eventuales "efectos secundarios" dada la volatilidad de la inflación como indicador a partir del cual el sistema UPAC calculaba la indexación del capital financiero colocado en créditos de vivienda; lo cierto es que la intervención de las CAV permitieron la consolidación del sector de la construcción de vivienda como un renglón dinamizador de la economía, e incluso, como un mecanismo macroeconómico para fomentar la redistribución del ingreso a través de la generación de empleos masivos que apalancarían el surgimiento de una clase media que se constituiría, con el tiempo, en potencial beneficiaria de créditos de vivienda. Es así como, para la segunda mitad de la década del setenta, el 70\% de los recursos que canalizaba el sector de la construcción provenían de las CAV; de igual forma -según Camacol- para el año 1981 el sistema CAV captó \$38 392000000 en

12 "Índice que permite mantener el valor de los recursos que maneja el sistema de valor constante UPAC, y se aplica a rentabilidad de los ahorros como para los costos que canalizan los créditos de las corporaciones de ahorro y vivienda" (2006, p. 145). 
depósitos de ahorros, incrementando en un 45\% el indicador del año inmediatamente anterior (Santana, 1982; Fique, 2008).

Para la década de los ochenta era claro que el modelo financiero para la construcción de vivienda -ofertado por las CAV-, terminó por encontrar su nicho de mercado en una clase media y media alta que no se veían representadas ni interesadas en los modelos de política de vivienda de gobiernos precedentes, dando lugar ello a un cierre financiero trinitario bastante fructífero y rentable, entre: i) un sector económico con capacidad de pago totalmente inexplorado y urgido de soluciones de vivienda; ii) una Banca Privada con boyantes recursos; y iii) las condiciones de retorno de la utilidad financiera de los grandes capitales garantizados a través del UPAC.

Sin embargo, la historia se encargaría de enseñar que la simetría de dicho mercado 'cuasi-perfecto' terminaría por desdibujarse con la marcada tendencia al alza en el precio de las viviendas, en principio, suntuosas, esto es, aquellas viviendas demandadas por la clase media y media-alta, lo cual implicaba mayor tasa de esfuerzo de los ahorradores beneficiarios de los créditos y, por lo general, mayor utilidad para las CAV, los propietarios de lotes y las firmas constructoras gracias a su posición privilegiada en el sector. Esta distorsión del mercado se explica por el proceso de especulación que envolvió al sector de la construcción de viviendas financiadas a través del sistema financiero, y que se podría sintetizar en las siguientes maniobras: i) Prácticas de manipulación de las condiciones del crédito por parte de las CAV para aumentar el monto del total de los intereses pagados por el beneficiario del crédito. ii) El establecimiento de costos financieros elevados e injustificados y cargados a las operaciones de crédito de los ahorradores y los constructores. iii) La expansión del rango de acción de algunas $\mathrm{CAV}$, que constituyeron firmas constructoras al estructurar así la concentración de utilidades, y dar lugar a prácticas de monopolio. iv) La especulación con el valor de lotes urbanizables y de futuras zonas de expansión urbana. v) Los costos de utilidad que le imprime el constructor al precio unitario de la vivienda. vi) El establecimiento de referentes de utilidad derivados de la venta de viviendas suntuosas a la clase alta, que se aplican a la vivienda para la clase media. vii) La práctica de garantizar la utilidad a costa de la calidad en el caso de producción de viviendas de menor envergadura. y viii) La evidente práctica del lavado de activos producto del tráfico de estupefacientes en el sector inmobiliario con los subsiguientes efectos inflacionarios que este comporta.

De igual forma, el incremento en la producción de vivienda que caracterizó a esta etapa de la política trajo consigo un desabastecimiento de materiales e insumos para la construcción, problema que terminó por impactar el costo de las unidades de vivienda y contribuir al fenómeno inflacionario del mercado inmobiliario anotado.

Ante el acaparamiento del mercado del ahorro por parte de las CAV, el modelo de intervención del cuadro de instituciones estatales se reorientó a satisfacer las necesidades del sector marginal de los grandes centros poblados del país, y a atender las deficiencias de vivienda en el sector rural. Es así como, entre el año de 1973 y 1989, el BCH se focalizó en ofrecer créditos mediante el sistema UPAC al sector 
asalariado urbano y rural, incorporándose así en el mercado de las corporaciones de ahorro y vivienda; igualmente, desarrolló una estrategia de crédito concentrado mediante la cual constructores, compradores y el Banco efectuaban el cierre financiero para proyectos de vivienda específicos. Asimismo, se lanzó la estrategia de cédulas de inversión para fomentar el ahorro de familias residentes en inquilinatos que, beneficiadas con el programa de arriendos congelados, podrían empezar a capitalizar mediante dichos títulos con miras a acceder a créditos de vivienda en el mismo Banco Central. De igual forma, las alianzas estratégicas entre las cajas de compensación familiar, las cooperativas, los fondos de empleados y el $\mathrm{BCH}$ se ofrecieron como alternativas para generar vivienda a precio de costo $\mathrm{y}$, por último, el $\mathrm{BCH}$ amplió su compás de intervención al desarrollar líneas de crédito para la construcción de proyectos de infraestructura, renovación urbana y recuperación de los sectores históricos de las principales ciudades del país, a través de su fondo financiero (Ceballos, 2008).

El Estado, en el mismo lapso del 1973 a 1989, reorientó el papel del ICT, dirigiendo el crédito ofertado a financiar modelos de autoconstrucción y de desarrollo progresivo de barrios populares, en el marco de lo dispuesto por el Decreto 710 de 1973; este Instituto se ocupó de la incorporación progresiva de zonas subnormales en proceso de crecimiento, la construcción de vivienda popular, la instalación de equipamientos comunitarios, el mejoramiento de vivienda y la financiación de proyectos multifamiliares, como estrategias para superar los costos del suelo y optimizar la inversión estatal. Así mismo, fue notorio el liderazgo del ICT en el desarrollo del programa de viviendas sin cuota inicial, implementado en el periodo del presidente Belisario Betancur Cuartas (1982-1986), con el cual se alcanzó un índice de construcción de 162746 viviendas para la población de escasos recursos.

Por otra parte, en la década de los setenta y ochenta se adoptaron medidas significativas orientadas a armonizar y organizar la confluencia de actores públicos y privados en el marco de la política pública de vivienda de la época, y ganar así mayor cobertura y eficacia; entre estas se encuentran la Formulación de planes específicos tendientes a mejorar las condiciones de habitabilidad del sector rural como lo fue el Programa de Desarrollo Rural Integrado (DRI) y el Fondo de Vivienda Rural, administrado por la Caja de Crédito Agrario, el cual fue creado mediante la Ley 20 de 1976-; Medidas de fortalecimiento a las CAV como el incentivo en el aumento en las tasas de interés, la disminución de los impuestos retenidos y la reducción de los encajes sobre los certificados de depósito a término; Medidas para orientar el modelo UPAC a sectores de bajos ingresos; La implementación de planes específicos para incentivar la construcción masiva de proyectos de vivienda en las grandes ciudades - como lo fue el Plan Indicativo de Edificación de Vivienda, encaminado a conformar alianzas estratégicas entre actores del sector- $y$, Medidas de regulación en busca de disminuir los costos directos e indirectos en la producción 
de vivienda, mejorar el flujo de insumos y materiales, desarrollar una estrategia de reserva de lotes aptos para la construcción de grandes proyectos, y la promoción de la vivienda multifamiliar como mecanismo eficiente para la reducción del déficit cuantitativo de vivienda. Asimismo, fue expedida la Ley 9 de 1989, Ley de Reforma Urbana pionera en Latinoamérica, y se descentralizó funcional y territorialmente el modelo de intervención estatal con la reforma constitucional de 1988, que permitió la elección de alcaldes, gobernadores y erigió la autonomía política y administrativa de las regiones del país, como un principio para el desarrollo eficaz y eficiente en la atención de las necesidades básicas insatisfechas en las regiones (Ceballos, 2008).

No obstante, el esfuerzo del Estado por reorientar el alcance de las instituciones públicas del sector en procura de facilitar la inclusión de los sectores marginales al modelo financiero de producción de vivienda que se instaló -y acapararon las CAV-, lo cierto es que en este periodo el papel del ICT y el BCH se vio bastante menguado con respecto a los índices de producción de vivienda para las clases asalariadas, media y alta beneficiadas con el UPAC. Asimismo, la instrumentalización del sector de la construcción como mecanismo jalonador de la economía en la política macroeconómica del país, terminó siendo un arma de doble filo para los sectores marginales expectantes de la oferta de vivienda financiada desde las instituciones públicas, en la medida en que la recesión propia del mercado inmobiliario culminó ocupando la atención y los esfuerzos políticos, administrativos y financieros de los gobiernos, que veían en las profundas recesiones una amenaza estructural prevaleciente frente a la necesidad de fortalecer la política de vivienda de interés social.

En este periodo se puede observar un modelo de política semi-intervencionista inspirado en las bondades del esquema de alianza público-privada, encaminado a fortalecer la generación de vivienda y satisfacer la incesante demanda, en razón a lo cual se establecieron importantes incentivos financieros y tributarios para atraer la inversión de capital privado en el sector, a través del modelo económico de las CAV, ofreciéndoles a ellas suficientes garantías de rentabilidad, y así estimular la inversión de sus cuantiosos recursos en un renglón de la economía donde existía mucho por hacer. Así las cosas, diagramando este periodo encontramos cambios sustanciales en el cuadro de actores de la política, que pasa de ser esencialmente institucional y centralizada a ser compuesta y semi-intervencionista: 
Figura 3. Modelo organizacional en la política de vivienda por el sistema UPAC

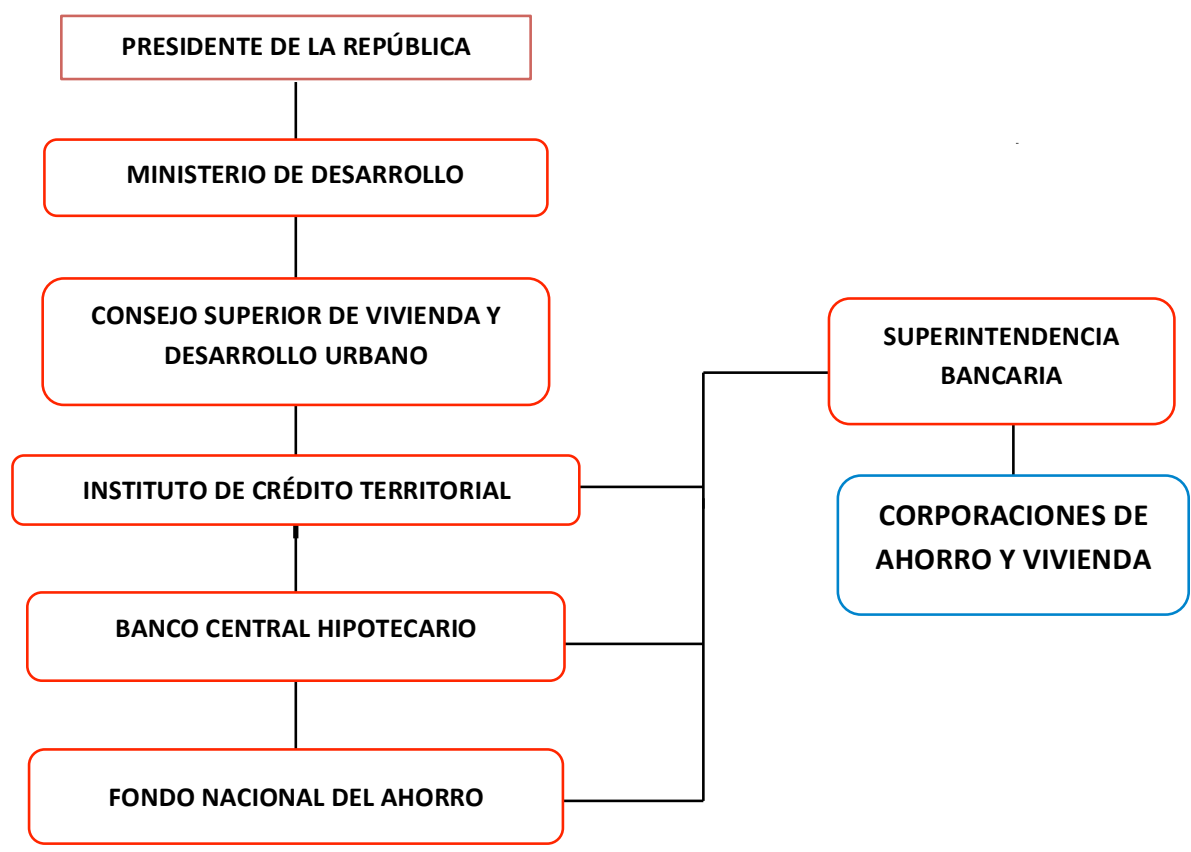

Fuente: elaboración propia.

\section{Los modelos asociativos de producción de vivienda en el periodo de las corporaciones de ahorro y vivienda}

Los modelos asociativos de producción de vivienda de interés social, en medio de este periodo de auge y expansión del Sistema Financiero Privado en la Política, se mostraron como una alternativa eficiente para el desarrollo progresivo de soluciones de vivienda en sectores subnormales y en zonas de expansión urbana a través de esquemas de gestión de proyectos como la autoconstrucción y lotes con servicios. Así mismo, se promovió el fortalecimiento de los modelos cooperativos mediante la capacitación laboral y el fortalecimiento de las organizaciones comunales para el desarrollo de proyectos de vivienda en los sectores marginales.

En una economía que se esforzaba por ser cada vez más industrializada y que además se iba incorporando en el mercado global de capitales y bursátil -con una clara dependencia de los sistemas financieros y la bancarización para la consolidación en sus 
relaciones económicas-, se terminaron por agudizar las condiciones de marginalidad de la población de escasos recursos que, ya excluida del mercado laboral formal, ahora lo eran también del sistema financiero provisto como plataforma para fomentar la oferta de vivienda de interés social. Ante tal panorama, los modelos asociativos de gestión de vivienda se convierten en una alternativa crucial para atender la necesidad de vivienda adecuada en estas capas poblacionales, que solo a partir de su capacidad de organización y gestión -en algunos casos apoyada por el Estado-, ven salidas reales a su problemática.

Para la segunda mitad de la década de los ochenta, las acciones sociales colectivas en procura de satisfacer la necesidad de viviendas adecuadas para los grupos poblacionales marginados de la política pública, lograban un importante nivel de estructuración y sofisticación, dando lugar a la conformación de tres tipologías organizacionales de vivienda con carácter y objetivos distintos pero complementarios:

1. Organizaciones de autodesarrollo: estas emergen de los sectores populares con el propósito de generar procesos de desarrollo al interior de sus comunidades. Son las denominadas organizaciones de base o de primer nivel, en la medida que son los adjudicatarios de planes oficiales, inquilinos y habitantes piratas, subnormales y normalizados.

2. Organizaciones de atención, apoyo y acompañamiento: esta tipología de organizaciones surge fuera del ámbito de las comunidades populares hacia las cuales dirigen sus acciones. Tienen como objetivos fortalecer y potenciar el accionar de las organizaciones populares de bases y conforman las organizaciones de segundo nivel por medio de cooperativas de vivienda, ahorro y crédito y otras formas asociativas, las cuales desarrollan planes de construcción y mejoramiento de vivienda; así mismo, cuentan con sistemas de crédito para sectores con cierta capacidad de pago.

3. Coordinación institucional y representación gremial: estas organizaciones consideradas como de tercer nivel brindan su apoyo a los sectores populares en la articulación con el Estado. Están constituidas por Fundaciones y ONG orientadas principalmente hacia la asistencia legal, técnica y el diseño de programas de vivienda (Reyes, 1999, p. 2, citado en Vélez, 2012).

Ahora bien, dada la intensidad con la que se manifestó el modelo asociativo de producción de vivienda en los sectores populares, y su importancia dentro de los instrumentos de gestión de vivienda que conformaban la oferta pública de la época, es expedido el Decreto 2391 de 1989, reglamentario del artículo 62 de la Ley 9 de 1989, mediante el cual se regularon e institucionalizaron las organizaciones populares de vivienda, trayendo ello aparejado su reconocimiento, visibilidad y legalidad; pero, igualmente, trajo consigo obstáculos burocráticos, mayores costos administrativos, inflexibilidad, subordinación organizacional, obstruyendo en algunos casos su dinámica y fluidez como acción social colectiva. 
De hecho, el artículo 62 de la Ley 9 de 1989 establece:

Son organizaciones populares de vivienda aquellas que han sido constituidas y reconocidas como entidades sin ánimo de lucro, cuyo sistema financiero es de economía solidaria y desarrollan programas de vivienda para sus afiliados por medio de sistemas de autogestión o participación comunitaria.

Estas organizaciones pueden ser constituidas por sindicatos, cooperativas, asociaciones, fundaciones, corporaciones, juntas de acción comunal, fondos de empleados, empresas comunitarias y las demás que puedan asimilarse a las anteriores, en los términos previstos por la ley. Las organizaciones deberán ejecutar sus planes de vivienda en terrenos aptos para el desarrollo urbano y de conformidad con todas las normas técnicas, urbanísticas y arquitectónicas vigentes en la localidad.

Las entidades que vigilen las actividades de dichas organizaciones, en los términos del Decreto Ley 78 de 1987 y demás disposiciones sobre el régimen comunitario, adoptarán un reglamento especial que permita la recepción anticipada de dineros de sus compradores para adelantar sus planes, y que a la vez resguarde suficientemente los derechos de quienes confíen sus dineros a ellas.

Los artículos 1, 6 y 7 del Decreto 2391 de 1989, aún vigentes, establecen:

Artículo 1: Definición de Organizaciones Populares de Vivienda: Se entiende por organizaciones populares de vivienda aquellas que han sido constituidas y reconocidas como entidades sin ánimo de lucro, cuyo sistema financiero sea de economía solidaria y tengan por objeto el desarrollo de programas de vivienda para sus afiliados por medio de sistemas de autogestión o participación comunitaria.

Estas organizaciones pueden ser constituidas por sindicatos, cooperativas, asociaciones, fundaciones, corporaciones, juntas de acción comunal, fondos de empleados, empresas comunitarias y las demás que puedan asimilarse a las anteriores, en los términos previstos por la Ley $9^{\text {a }}$ de 1989.

Artículo $6^{\circ}$. Obligaciones de las Organizaciones Populares de Vivienda ante la Superintendencia de Sociedades: Las Organizaciones Populares de Vivienda deberán cumplir con las siguientes obligaciones ante la Superintendencia de Sociedades:

1) Presentación anual de estados financieros, suscritos por el representante legal y contador público, debidamente aprobados por el máximo órgano de la entidad. 2) Envío del presupuesto de gastos e inversiones por cada año, 
con la constancia de aprobación del órgano social correspondiente, antes del primer día hábil del mes de mayo. 3) Relación de ingresos y egresos trimestral, con indicación del total recaudado por concepto de cuotas de vivienda y de las otras fuentes de financiación, debidamente discriminadas.

4) Prueba del registro de los nombramientos ante las autoridades competentes: en el caso de las cooperativas, certificación de Dancoop; para las asociaciones y fundaciones, certificación de la Alcaldía Mayor de Bogotá o de las gobernaciones; para las juntas de vivienda comunitaria, certificación del Ministerio de Gobierno. En el caso de las cooperativas, certificación de Dancoop; para las asociaciones y fundaciones, certificación de la Alcaldía Mayor de Bogotá o de las gobernaciones; para las Juntas de Vivienda Comunitaria, certificación del Ministerio de Gobierno.

Artículo $7^{\circ}$. Registro para Desarrollar Planes y Programas por los Sistemas de Autogestión o Participación Comunitaria: Para desarrollar planes y programas por los sistemas de autogestión o participación comunitaria, las organizaciones populares de vivienda deberán registrarse ante la Alcaldía Mayor del Distrito Especial de Bogotá, la Intendencia de San Andrés y Providencia o en la alcaldía municipal del lugar donde se realice la obra. El registro se hará por una sola vez y se entenderá vigente por todo el término de duración de la organización popular de vivienda o hasta que la organización solicite su cancelación, a menos que le sea cancelado como consecuencia de las sanciones establecidas para este efecto.

Resulta paradójico que el reconocimiento legal de los modelos asociativos de vivienda y de la filosofía de la economía solidaria, manifiesta con la expedición del Decreto 2371 de 1989, se enmarque en la apuesta que nuestro país le hace a la economía del mercado y de apertura económica que reescribió la escena política, social y económica de los países suramericanos en vía de desarrollo a partir de la década de los noventa, década en la cual se fomentó una profunda reestructuración en la Política Pública abandonando cualquier intervencionismo institucional en la producción de vivienda de iniciativa estatal para, en cambio, instaurar una política edificada en los subsidios económicos a la demanda en procura de capitalizarla, y mejorar así sus posibilidades de crédito e ingreso al mercado de la vivienda de interés social.

Ajustándose al paradigma de la economía de mercado y de la apertura económica, se expide la Ley 3 de 1991, por medio de la cual: "Se establece el Sistema Nacional de Vivienda de Interés Social", actualmente vigente en Colombia, el cual, se expondrá en sus aspectos generales en el título siguiente. 


\section{EL SISTEMA NACIONAL DE VIVIENDA: LEY 3 DE 1991 Y LA PROMOCIÓN DE LOS MODELOS ASOCIATIVOS DE VIVIENDA}

\section{Principios y finalidades de la política de subsidios a la demanda}

El Sistema Nacional de Vivienda (SNV) es un tipo de política pública que responde a los postulados y al marco ideológico del modelo de desarrollo económico del libre mercado, promovido en Colombia desde la década del noventa y con fundamento en el cual se le ha atribuido un valor estratégico y fundamental a la incursión de los agentes económicos privados en el desarrollo de las políticas encaminadas a satisfacer y mejorar la calidad de vida de la población.

En este modelo son abandonados los esquemas de políticas intervencionistas fundados en la estatalización de los programas de impacto social y de provisión de bienes y servicios encaminados a atender al grueso de la población, dando en cambio cabida a la iniciativa de agentes económicos privados en capacidad de mejorar el desempeño de las instituciones públicas -en términos de eficiencia, efectividad y costos-, y siendo estas últimas objeto de inspección y vigilancia por parte de las entidades reguladoras en cada sector.

En el ámbito de la política de vivienda, la implantación del modelo de desarrollo de mercado implicó una reestructuración de gran calado en el cuadro institucional público, dio lugar a su vez a la liquidación del ICT, el BCH y el INURBE, explicable en parte por sus difíciles condiciones de operatividad y desempeño, a causa de fenómenos de burocratización, politización y desaciertos en la toma de decisiones; igualmente, su inflexibilidad operativa les impidió encarar un sistema que promovía la libre competencia en el sector.

Atendiendo los postulados de este nuevo marco ideológico, el SNV se centra en el propósito de mejorar la capacidad adquisitiva de las familias de escasos recursos, como presupuesto esencial para posibilitarles el acceso a la vivienda en un sistema económico de mercado. Se vale para ello, principalmente, de un aporte estatal en dinero o en especie a título de subsidio familiar, la disposición de una oferta de crédito pública y privada con tasas de interés controladas, y la generación de estímulos para incentivar la incursión de actores privados en el campo inmobiliario, y de la construcción a fin de consolidar una oferta de vivienda a precios asequibles para la población de escasos recursos.

\section{Sus instrumentos, subsistemas y modelo organizacional}

De acuerdo con lo estipulado en su artículo $2^{\circ}$, el sistema estará integrado por los subsistemas de: i) Fomento o ejecución: compuesto por los entes territoriales descentralizados, organizaciones populares de vivienda, organizaciones no gubernamentales (ONG), empresas privadas y los establecimientos públicos 
especializados en materia de vivienda y desarrollo territorial -como el naciente INURBE-, el Fondo Nacional del Ahorro, la Caja de Vivienda Militar y las empresas de servicios públicos; todos estos entes involucrados en los procesos de diseño, planeación y ejecución de programas y planes de vivienda de interés social. ii) Subsistema de Asistencia Técnica y Promoción a la Organización Social compuesto igualmente por los entes territoriales, las agremiaciones de las OPV, entidades privadas que presten asistencia técnica, el IGAC, el Centro Nacional de la Construcción (Cenac), la ESAP y las universidades con desarrollos investigativos en el sector. iii) Por último, el Subsistema de Financiación compuesto por las Entidades Financieras Públicas y Privadas con líneas de ahorro, crédito, descuento, redescuento y subsidios destinados a proveer vivienda de interés social, así como la Financiera de Desarrollo Territorial (Findeter), el BCH, la Caja Agraria y las Cajas de Compensación Familiar que participan en la gestión financiera del sistema.

Con la incorporación al Sistema Nacional de Vivienda en 1991 es reemplazado el ICT por el Instituto de Vivienda de Interés Social y Reforma Urbana (Inurbe) ${ }^{13}$, medida administrativa que anunciaba la reestructuración inminente del andamiaje institucional concebido bajo el modelo de la política de intervención estatal, lo anterior, en vista de los fenómenos de burocratización y politización que habían cooptado la capacidad de gestión del ICT, evidenciando sobrecostos en su operación, ineficacia e ineficiencia generalizada en el cumplimiento de sus cometidos institucionales, frente a una realidad que mostraba déficit cuantitativos y cualitativos de vivienda verdaderamente dramáticos.

Igualmente, con las reformas introducidas al sistema mediante el Decreto 554 del 2003 el Inurbe, que tenía por funciones principales: i) Promover la aplicación de la Ley 9 de 1989. ii) Prestar asistencia técnica y financiera a las administraciones locales y a las OPV. iii) Administrar los recursos nacionales de subsidio familiar. iv) Coordinar con las entidades del Sistema y la Caja de Crédito Agrario lo atinente a la confluencia de créditos y subsidios para la vivienda. v) Administrar los recursos del subsidio de manera coordinada con las administraciones locales para la cofinanciación de proyectos de vivienda. vi) Otorgar créditos a los fondos de vivienda municipal, OPV y entidades ejecutoras a través de intermediarios financieros para desarrollar proyectos de vivienda; entre otras funciones. Fue liquidado en el Gobierno del presidente Álvaro Uribe Vélez y reemplazado por el Fondo Nacional para la Vivienda (Fonvivienda), creado mediante el Decreto 555 del 2003.

13 Artículo 10 de la Ley 3 de 1991: “A partir de la vigencia de la presente Ley, el Instituto de Crédito Territorial (ICT) se denominará Instituto Nacional de Vivienda de Interés Social y Reforma Urbana (Inurbe). Para todos los efectos legales las actuaciones administrativas adelantadas por el Instituto de Crédito Territorial, con anterioridad a la vigencia de la presente Ley, se entenderán realizadas a nombre del Instituto Nacional de Vivienda de Interés Social y Reforma Urbana (Inurbe). El Instituto mantendrá su naturaleza de establecimiento público del orden nacional, con personería jurídica, autonomía administrativa y patrimonio propio e independiente, adscrito al Ministerio de Desarrollo Económico". 
Bajo la misma lógica y como efecto del coletazo de la crisis económica de la década de los noventa, la cual tuvo por epicentro al sector financiero bajo el sistema UPAC, es liquidado el Banco Central Hipotecario, al que la Ley 3 de 1991 le había asignado las siguientes funciones de acuerdo con lo estipulado en su artículo 15:

El BCH tendrá por objeto captar ahorro y financiar con prioridad la compraventa de vivienda usada, la integración inmobiliaria, el reajuste de tierras, la rehabilitación de inquilinatos y los programas de remodelación, ampliación y subdivisión de vivienda. También podrá realizar las operaciones autorizadas a las corporaciones de ahorro y vivienda, las operaciones de descuento y redescuento de que trata el artículo 119 de la Ley 9a de 1989, para lo cual creará y administrará un fondo especial, y canalizará los recursos de ahorro que el Gobierno decida aplicar a la financiación de la política de vivienda de interés social y prestar servicios financieros ${ }^{14}$.

Actualmente, el modelo institucional que integra el Sistema Nacional de Vivienda de Interés Social está compuesto por entidades integradoras y coordinadoras de políticas públicas, entidades de financiamiento, entidades de asistencia técnica, entidades otorgantes de créditos y subsidios, entidades de regulación y control, cuya interacción se puede dimensionar en el siguiente cuadro:

14 Artículo 15, Ley 3 de 1991: “El Banco Central Hipotecario, como integrante del Sistema Nacional de Vivienda de Interés Social, tendrá por objeto captar ahorro y financiar con prioridad la compraventa de vivienda usada, la integración inmobiliaria, el reajuste de tierras, la rehabilitación de inquilinatos y los programas de remodelación, ampliación y subdivisión de vivienda. También podrá realizar las operaciones autorizadas a las corporaciones de ahorro y vivienda, las operaciones de descuento y redescuento de que trata el artículo 119 de la Ley 9a de 1989, para lo cual creará y administrará un fondo especial, canalizar los recursos de ahorro que el Gobierno decida aplicar a la financiación de la política de vivienda de interés social y prestar servicios financieros. Facúltese a la Junta Monetaria para expedir el reglamento especial de colocaciones del Banco Central Hipotecario para el cumplimiento de su objeto. El Banco podrá continuar los programas de construcción y de fiducia inmobiliaria contratados antes de la vigencia de la presente Ley, y excepcionalmente ejecutar proyectos de construcción de vivienda por encargo de su Junta Directiva con el voto favorable indelegable del Ministro de Hacienda y Crédito Público, y del Ministro de Desarrollo Económico. 
Figura 4. Modelo organizacional en el Sistema Nacional de Vivienda

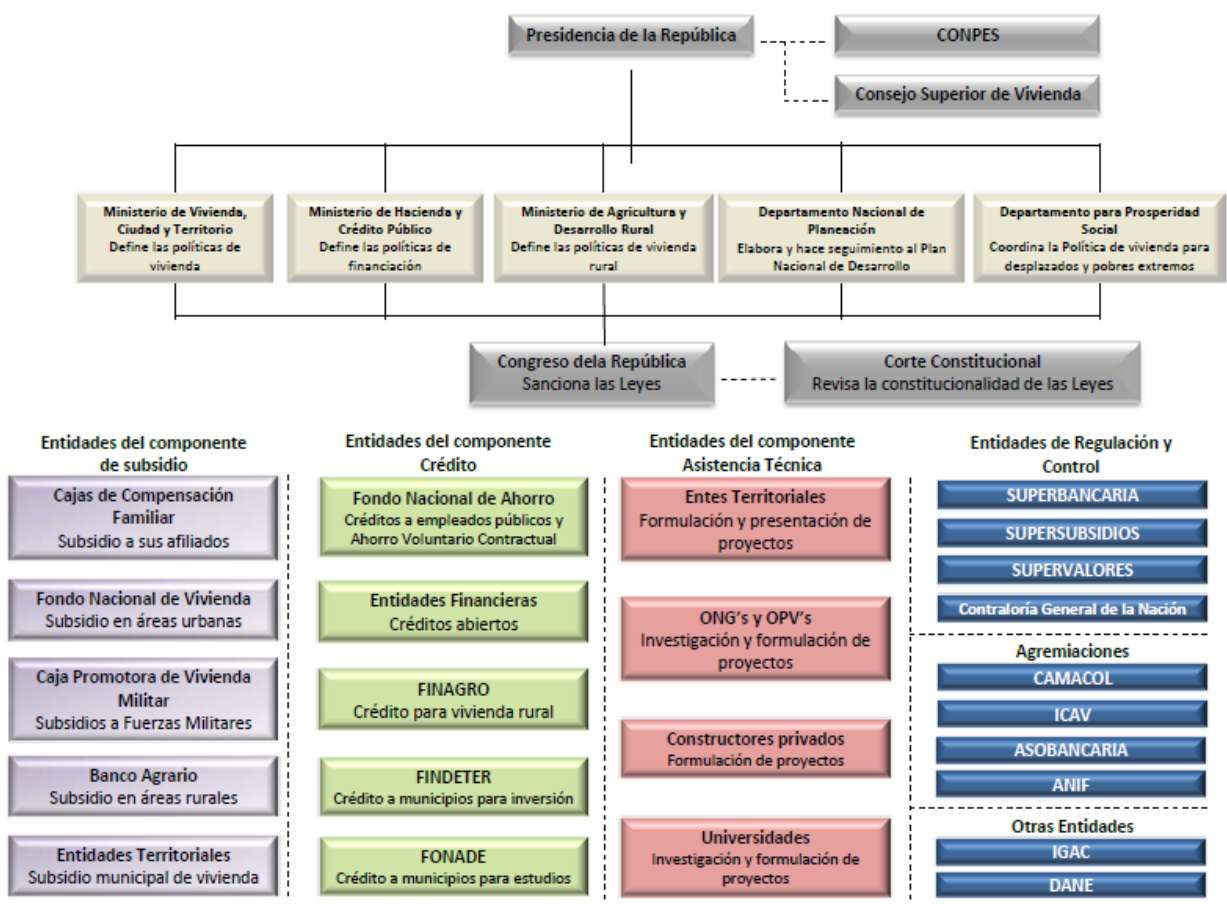

Fuente: Departamento Nacional de Planeación, 2014.

Por definición, el sistema demanda la coordinación funcional de los actores que interactúan en el proceso de producción de la oferta de vivienda de interés social, al ser su columna vertebral el subsidio otorgado a las familias de condiciones socioeconómicas vulnerables, las cuales -a partir del ahorro, el esfuerzo de los entes territoriales, el acceso al crédito y el desarrollo del proyecto técnica y constructivamente por actores privados como las cajas de compensación familiar, las cooperativas, firmas constructoras, entidades financieras $\mathrm{u}$ Organizaciones Populares de Vivienda-, deberían poder acceder a la adquisición del inmueble y así materializar su derecho constitucional de acceso a la vivienda adecuada ${ }^{15}$.

Como se ha mencionado, el sistema parte de una concepción del papel del Estado orientada a la coordinación, regulación y dirección del sistema de vivienda entendido como un organismo en el que interactúan los actores públicos y privados que movilizados por una dinámica de mercado promoverán una mejor oferta de vivienda social en el país. Ahora bien, la política pasa por el afianzamiento del proceso de descentralización administrativa del Estado, que venía en tránsito desde

15 El concepto de vivienda adecuada surge en la Segunda Conferencia sobre Asentamientos Humanos, denominada Hábitat II, realizada en Estambul (Turquía) en 1996. 
la expedición de la Ley 9 de 1989 -y se consolidó con la Constitución de 1991-, con la cual el papel del municipio como unidad política y administrativa nuclear de la Nación se vio exaltado, asumiendo, entre otras, la función de dirigir, regular, desarrollar y materializar los postulados del SNV previsto en sus planes municipales de desarrollo.

Igualmente, el artículo 17 de la Ley 3 de 1991 -modificado a su vez por el artículo 96 de la Ley 617 del 2000-, autoriza a los municipios para que constituyan un Fondo de Vivienda Social y Reforma Urbana, el cual tendrá por objeto

desarrollar las políticas de vivienda de interés social en las áreas urbanas y rurales, aplicar la Reforma Urbana en los términos previstos por la Ley 9 de 1989 y demás disposiciones concordantes, especialmente en lo que hace referencia a la vivienda de interés social, y promover las organizaciones populares de vivienda" (artículo 18 de Ley 3 de 1991).

Del mismo modo, le compete coordinar con los demás actores del sistema el desarrollo de la política de vivienda en el municipio, administrar los recursos del subsidio familiar de vivienda en los proyectos realizados por el fondo, implementar en asocio con entidades autorizadas proyectos de vivienda, mejoramientos o venta de vivienda usada $y$, promover el desarrollo de las organizaciones populares de vivienda, entre otras.

Asimismo, con la expedición de la Ley 388 de 1997 que creó los Planes de Ordenamiento Territorial, corresponde a los municipios "la definición de los programas de solución de VIS, disponibilidad de suelos urbanos no solo en lo referente a sanear el déficit habitacional, sino también a crear un entorno adecuado en infraestructura y servicios a los ciudadanos, es decir, mejorar el hábitat"; así mismo, le fueron asignadas, entre otras, las siguientes funciones específicas en materia de promoción y control de vivienda: i) El ordenamiento del territorio municipal (Ley 388 de 1997) ${ }^{16}$. ii) Formulación y adopción de los planes de ordenamiento territorial (Ley 388 de 1997) $)^{17}$. iii) La actualización urbana (Ley 388 de 1997) ${ }^{18}$. y iv) El desarrollo

16 Artículo $5^{\circ}$. Concepto. El ordenamiento del territorio municipal y distrital comprende un conjunto de acciones político-administrativas y de planificación física concertadas y emprendidas por los municipios o distritos y áreas metropolitanas, en ejercicio de la función pública que les compete, dentro de los límites fijados por la Constitución y las leyes, en orden a disponer de instrumentos eficientes para orientar el desarrollo del territorio bajo su jurisdicción, y regular la utilización, transformación y ocupación del espacio, de acuerdo con las estrategias de desarrollo socioeconómico, y en armonía con el medio ambiente y las tradiciones históricas y culturales.

17 Artículo $9^{\circ}$. Plan de ordenamiento territorial. El plan de ordenamiento territorial que los municipios y distritos deberán adoptar en aplicación de la presente ley, al cual se refiere el artículo 41 de la Ley 152 de 1994, es el instrumento básico para desarrollar el proceso de ordenamiento del territorio municipal. Se define como el conjunto de objetivos, directrices, políticas, estrategias, metas, programas, actuaciones y normas adoptadas para orientar y administrar el desarrollo físico del territorio y la utilización del suelo.

18 Artículo36. Actuación urbanística pública. Son actuaciones urbanísticas la parcelación, urbanización y edificación de inmuebles. Cada una de estas actuaciones comprenden procedimientos de gestión y formas de ejecución que son orientadas por el componente urbano del plan de ordenamiento, 
y construcción de vivienda prioritaria mediante la aplicación de instrumentos como la figura de la enajenación forzosa por la incursión en causal de incumplimiento del deber social de la propiedad del artículo 52; la enajenación voluntaria, expropiación judicial y expropiación administrativa para el desarrollo de obras de utilidad pública, entre otros.

Los departamentos pueden concurrir a la financiación de proyectos de vivienda con los municipios y ofrecer asistencia técnica, administrativa y operacional en los casos en que sea requerido, según lo estipulan los artículos 23 y 24 de la Ley 3 de 1991; asimismo, son creados como instancia departamental de coordinación y desarrollo de la política los consejos departamentales de vivienda de interés social, órganos asesores en asuntos técnicos, administrativos, financieros, jurídicos y políticos para la promoción de proyectos de vivienda de interés social en cada región.

El subsidio de vivienda, entendido como la subvención en dinero (Ley 3 de 1991) ${ }^{19}$ o en especie que el Estado le otorga a familias de condiciones socioeconómicas vulnerables, sin cargo a restitución, que han surtido el proceso de postulación, calificación y reconocimiento puede ser otorgado por Fonvivienda, el Banco Agrario, Findeter, Finagro, las cajas de compensación familiar o la entidad que el Gobierno Nacional designe según su inversión, sea para compra de vivienda usada, nueva, mejoramiento, adecuación o arrendamiento, en el sector rural o urbano, al ser dichas entidades las llamadas a concurrir con recursos económicos a título de subsidio en el sistema nacional; así mismo, como se ha mencionado, los departamentos, distritos y municipios, a partir de lo que el sistema ha denominado esfuerzo territorial, pueden aunar esfuerzos económicos en dinero o en especie para el desarrollo de proyectos de vivienda de interés social en su jurisdicción.

Los recursos económicos de origen financiero están a cargo de la banca comercial, que luego de la crisis financiera de los noventa reemplazó a las $\mathrm{CAV}$, ofreciendo créditos hipotecarios a las familias en tránsito de adquirir vivienda usada o nueva, o para ampliaciones o mejoras en lote propio. Así mismo, las cooperativas, fondos de empleados, Fondo Nacional del Ahorro o agremiaciones con programas de crédito que benefician a sus miembros, igualmente se convierten en actores económicos fundamentales a la hora de concretar el cierre presupuestal y financiero de proyectos de vivienda multifamiliar, para compra de un inmueble nuevo o usado, destinado a vivienda de interés social o para ampliaciones y mejoras de la vivienda propia.

El crédito financiero de vivienda es actualmente objeto de regulación, vigilancia,

y deben quedar explícitamente reguladas por normas urbanísticas expedidas de acuerdo con los contenidos y criterios de prevalencia establecidos en los artículos 13, 15, 16 y 17 de la presente ley.

19 Artículo 6o, modificado por la Ley 1469 de 2011, Art. 28. Establézcase el Subsidio Familiar de Vivienda como un aporte estatal en dinero o en especie, que podrá aplicarse en lotes con servicios para programas de desarrollo de autoconstrucción, entre otros, otorgado por una sola vez al beneficiario con el objeto de facilitar el acceso a una solución de vivienda de interés social o interés prioritario de las señaladas en el artículo $5^{\circ}$ de la presente ley, sin cargo de restitución, siempre que el beneficiario cumpla con las condiciones que establece esta ley. 
inspección y control por parte del Estado; en la medida en que las tasas de interés son controladas por el Banco de la República, la corrección monetaria del capital financiero es controlada mediante el sistema de Unidades de Valor Real (UVR), y la Superintendencia Financiera se encarga de verificar el cumplimiento de la normatividad específica sobre este tipo de créditos hipotecarios. De igual forma, se ofrecen garantías a la inversión financiera -como la figura del patrimonio de familia previsto en el artículo 6 de la Ley 9 de 1989 y en el artículo 38 de la Ley 3 de 1991-, que posibilita el embargo de los inmuebles adquiridos con cargo al crédito solo por la entidad financiera otorgante del mismo. Igualmente, se ofrecen garantías de estabilidad del crédito a los deudores contra fenómenos inflacionarios, como el seguro anti-inflacionario ofrecido por el Fogafín.

Importantes discusiones se han suscitado alrededor del carácter rentista y excluyente del recurso financiero invertido en el sistema, y la apuesta crítica que el Estado hace al erigirlo como un instrumento económico estructurante en la dinámica de la oferta de Vivienda Social, sin considerar lo restrictivo, selectivo e inaccesible que este puede ser para las familias de escasos recursos, que no logran consolidar una capacidad de pago que los visibilice ante el sistema financiero:

El problema que enfrenta el mercado de VIP radica en que buena parte de los hogares que potencialmente son objeto de la política de vivienda, es decir, aquellos hogares con ingresos inferiores a 4 SMMLV, no están pudiendo lograr el cierre financiero [...] Se aprecia que, adicional a las 4.9 millones de familias que se encuentran por debajo de la línea de pobreza, existe otro millón de hogares (aquellos con ingresos entre 1.3 y 2 SMML) que en condiciones normales de mercado serían incapaces de acceder a una VIP por medio del sistema vigente. En ese orden de ideas, la población objetivo de la política de vivienda se puede dividir en dos grandes grupos: los hogares con acceso a crédito y con posibilidades de ahorro, y los hogares sin posibilidad de cierre financiero (Chirivi, Ramírez Rodríguez y Torres, 2012, p. 4).

En tal sentido, actualmente son beneficiarias con el cierre financiero -vía acceso al crédito hipotecario- aquellas familias que reporten ingresos superiores a 2 SMLV, es decir, un total de 6.2 millones de hogares que equivalen al $54 \%$ de la población colombiana, según cifras del DANE y Camacol, siendo segregadas por el sistema el $46 \%$ restante de la familias que reportan déficit de vivienda.

Otro factor adverso en la dinamización de la oferta de VIS es la escasez de suelo urbanizable en condiciones satisfactorias de servicios públicos, infraestructura de transporte, condiciones topográficas, equipamiento urbanístico, entre otros requerimientos, que se encuentren disponibles para desarrollos masivos de vivienda a ofertar por parte de los actores del mercado a precios asequibles para la población de bajos ingresos. De la misma manera, el fenómeno de la especulación con el precio del suelo en las ciudades principales y en crecimiento a causa de las maniobras de acaparamiento que poderosos agentes económicos logran sobre bastas zonas de expansión que son convertidas en 'bancos inmobiliarios' o 'lotes de engorde', terminan por ahogar la posibilidad de consolidar una oferta de vivienda social suficiente y ajustada a la capacidad de pago de la demanda prioritaria. 
No obstante, la Ley 388 de 1997, en su artículo 8 (Ley 388 de 1997) ${ }^{20}$, faculta a los municipios para la constitución de áreas de reserva para el desarrollo de proyectos de VIS en las zonas de expansión urbana dimensionadas en los POT; dicho instrumento de planificación y gestión del suelo no ha sido del todo efectivo a la hora de frenar el fenómeno de especulación e inflación de su valor que, como se ha mencionado, es desatado por las maniobras de acaparamiento capitalista desplegadas por poderosos agentes económicos sobre la ciudad o debido a la frenética densificación formal e informal de las ciudades que termina por agotar las zonas de expansión urbana contribuyendo estos al encarecimiento del suelo.

Los indicadores de la curva ascendente en los precios del suelo hasta el año 2012 son reportados por Camacol y la Lonja de Bogotá, en los siguientes gráficos:

Figura 5. Cuadro indicativo de los precios del suelo en Bogotá

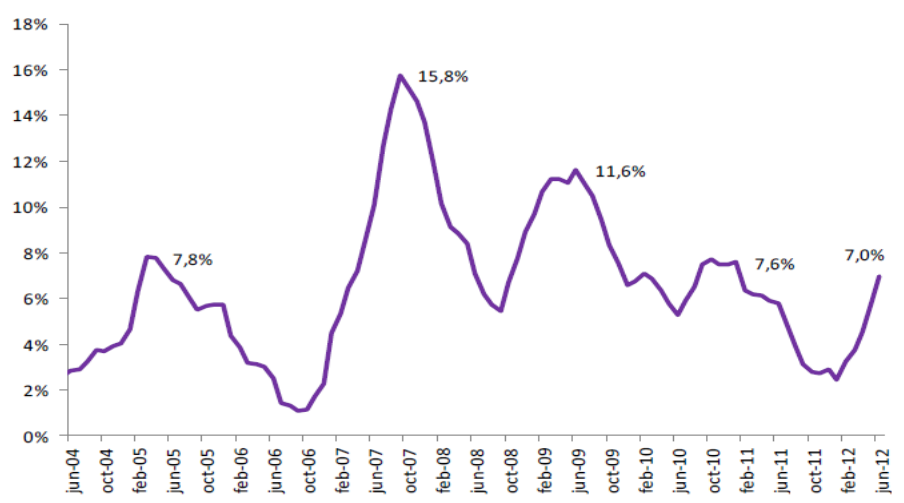

Fuente: Informe Económico No. 45 Camacol, 2012.

No obstante, el sistema del subsidio a la demanda y el modelo de desarrollo del liberalismo económico -sobre el cual se edifica la Política de Vivienda de Interés Social-, traen consigo distorsiones propias del mercado como la especulación con el suelo y la volatilidad en materiales para la producción de vivienda social; los

20 Artículo 8. Acción urbanística. La función pública del ordenamiento del territorio municipal o distrital se ejerce mediante la acción urbanística de las entidades distritales y municipales, referida a las decisiones administrativas y a las actuaciones urbanísticas que les son propias, relacionadas con el ordenamiento del territorio y la intervención en los usos del suelo. Son acciones urbanísticas, entre otras: [...] 7: Calificar y localizar terrenos para la construcción de viviendas de interés social; [...] 8: Calificar y determinar terrenos como objeto de desarrollo y construcción prioritaria. 9: Dirigir y realizar la ejecución de obras de infraestructura para el transporte, los servicios públicos domiciliarios y los equipamientos públicos, directamente por la entidad pública o por entidades mixtas o privadas, de conformidad con las leyes. 10: Expropiar los terrenos y las mejoras cuya adquisición se declare como de utilidad pública o interés social, de conformidad con lo previsto en la Ley. 
indicadores gubernamentales de asignación de subsidios muestran que las entidades del sistema, año tras año, incrementan sus esfuerzos por irrigar recursos en los segmentos de la población que requieren mejorar sus condiciones económicas para gozar de vivienda propia. A continuación, se muestran las cifras publicadas por el DNP 2013, al respecto:

Tabla 2. Subsidios familiares de vivienda asignados en el periodo 1991-2011

\begin{tabular}{|c|c|c|c|c|c|c|c|c|c|c|c|c|}
\hline \multirow{2}{*}{ AÑOS } & \multicolumn{3}{|c|}{ INURBEIFONVIVIENDA } & \multirow{2}{*}{$\begin{array}{c}\text { SUB. } \\
\text { PROMEDIO }\end{array}$} & \multicolumn{2}{|c|}{ BANCO AGRARIO } & \multicolumn{2}{|c|}{ C.C.F. } & \multicolumn{2}{|c|}{ C.P.M.M. } & \multicolumn{2}{|c|}{ F.N.A. } \\
\hline & Subsidios & titulos hit & Mill. (\$) & & Subsidios & Mill. (\$) & Subsidios & Mill (s) & Subsidios & Mill. (\$) & Subsicios & valor \\
\hline 1.991 & 17.402 & & 70.509 & $4051.775,66$ & & & 9.128 & 17.840 & 1.949 & 33.152 & & \\
\hline 1.992 & 40.313 & & 48.026 & $1.191 .327,86$ & 20.165 & 22.363 & 10.028 & 34.315 & 3.028 & 58.516 & & \\
\hline 1.993 & 57.490 & & 89.002 & $1.548 .130,11$ & 38.912 & 43.762 & 22.066 & 18.966 & 2.547 & 44.060 & & \\
\hline 1.994 & 65.760 & & 155.691 & $2367.563,87$ & 81.206 & 68.885 & 14.381 & 42.447 & 4.338 & 59.916 & & \\
\hline 1.995 & 71.380 & & 136.691 & $1.914 .976,18$ & 40.868 & 52.028 & 33.227 & 60.082 & 4.097 & 23.826 & 5.585 & 69.417 \\
\hline 1.996 & 49.390 & & 89.168 & $1.805 .385,71$ & 50.441 & 62.057 & 31.922 & 87.165 & 4.058 & 22.421 & 6.535 & 75.096 \\
\hline 1.997 & 57.479 & & 118.974 & $2069.869,00$ & 25.201 & 54.353 & 39.694 & 141.751 & 3.120 & 20.923 & 6.026 & 83.045 \\
\hline 1.998 & 19.966 & & 44.828 & $2245.216,87$ & 12.369 & 31.612 & 28.847 & 121.631 & 6.046 & 46.100 & 9.770 & 156.285 \\
\hline 1.999 & 21.369 & & 120.853 & $5.655 .529,04$ & 3.085 & 8.414 & 20.374 & 98.908 & 5.150 & 45.578 & 11.619 & 266.703 \\
\hline 2.000 & 22.226 & & 127.692 & $5.745 .163,32$ & 12.345 & 46.646 & 20.069 & 119.750 & 3.535 & 36.388 & 12.248 & 317.067 \\
\hline 2.001 & 32.139 & & 208.760 & $6.495 .535,02$ & 12.582 & 51.697 & 32.139 & 208.760 & 3.677 & 41.877 & 7.105 & 211.392 \\
\hline 2.002 & 15.012 & & 108.907 & $7.254 .662,94$ & 9.650 & 40.227 & 32.178 & 233.760 & 3.638 & 45.078 & 5.922 & 163.778 \\
\hline 2.003 & 20.423 & & 141.466 & $6.926 .798,22$ & 9.370 & 36.270 & 24.840 & 163.126 & 4.534 & 60.667 & 3.212 & 86.303 \\
\hline 2.004 & 36.761 & 736 & 256.064 & $6.965 .642,94$ & 14.979 & 67.537 & 32.696 & 181.541 & 4.793 & 70.562 & 8.722 & 235.178 \\
\hline 2.005 & 46.871 & 4.757 & 206.818 & $\begin{array}{l}4.412 .493,87 \\
\end{array}$ & 12.954 & 61.159 & 39.427 & 266.126 & 7.166 & 112.860 & 12.232 & 346.806 \\
\hline 2.006 & 34.899 & 938 & 298.691 & $8.558 .726,61$ & 12.882 & 68.028 & 48.796 & 342.274 & 6.101 & 104.439 & 15.713 & 410.071 \\
\hline 2.007 & 37.497 & 37.382 & 328.879 & $8.770 .808,33$ & 12.499 & 75.070 & 46.294 & 343.209 & 6.982 & 120.670 & 29.333 & 795.730 \\
\hline 2.008 & 46.484 & 89.283 & 379.021 & $8.153 .794,85$ & 10.445 & 73.413 & 46281 & 423.193 & 6.948 & 128.376 & 30.126 & 753.893 \\
\hline 2.009 & 27.471 & 83.051 & 272.519 & $9.920 .243,17$ & 1.224 & 10.293 & 47.734 & 476.178 & 6.408 & 146.242 & 54.844 & 1.235 .350 \\
\hline 2010 & 31.601 & 61.803 & 384.748 & $12.175 .184,33$ & 5.247 & 54.839 & 44.660 & 462.775 & 5.711 & 123352 & 88.987 & 2.225 .119 \\
\hline 2.011 & 28.292 & 6.319 & 395.647 & $13.984 .422,17$ & & & 36.236 & 384.117 & 5.250 & 120.461 & 35.016 & 1.039 .168 \\
\hline TOTAL & 780.225 & 284.269 & 3.982 .954 & 96.053 .644 & 386.444 & 928.653 & 661.017 & 4.227 .914 & 99.076 & 1.465 .454 & 307.979 & 7.431 .233 \\
\hline
\end{tabular}

Fuete electrónica: http://www.admonpublica.org/page/images/Documentos/Gestion/PrestarServicios/Vivienda/ subsidios_vivienda_1991_2011.pdf

Así mismo, según información del DNP 2013 para el año 2011 se construyeron 90 mil viviendas de Interés Social; para el año 2012, según información de la misma entidad, se otorgaron 78 mil licencias de construcción para Vivienda de Interés Social, y en el primer semestre del 2012 se construyeron 13 mil viviendas de este tipo, aproximadamente.

Ahora bien, pese a la apuesta que el Estado ha hecho en el subsidio a la demanda como mecanismo dinamizador para el mercado de la Vivienda Social, las realidades sociales del país han evidenciado que este modelo favorece a los segmentos de la población integrados a la economía formal constitutiva de una clase media emergente, o de una clase media consolidada que alcanza alguna estabilidad de ingresos económicos, siendo, en cambio, desatendido un importante segmento de la población en condición de pobreza extrema, pobreza moderada o en la línea de pobreza en los términos de las metodologías de medición unificadas por el DANE y el DNP ${ }^{21}$. Este segmento alcanza al 40\% de la población colombiana como se muestra en el siguiente gráfico:

21 Se han unificado las metodologías de medición de la pobreza, compatibilizando el método de Ravallion y el coeficiente de Orchansky ( $\left.\mathrm{LP}=\mathrm{LI} I^{*} \mathrm{CO}\right)$. Recuperado en: www.dane.gov.co/files/ noticias/Pobreza_nuevametodologia.pdf 
Figura 6. Caracterización de la población que es objeto de la política de vivienda

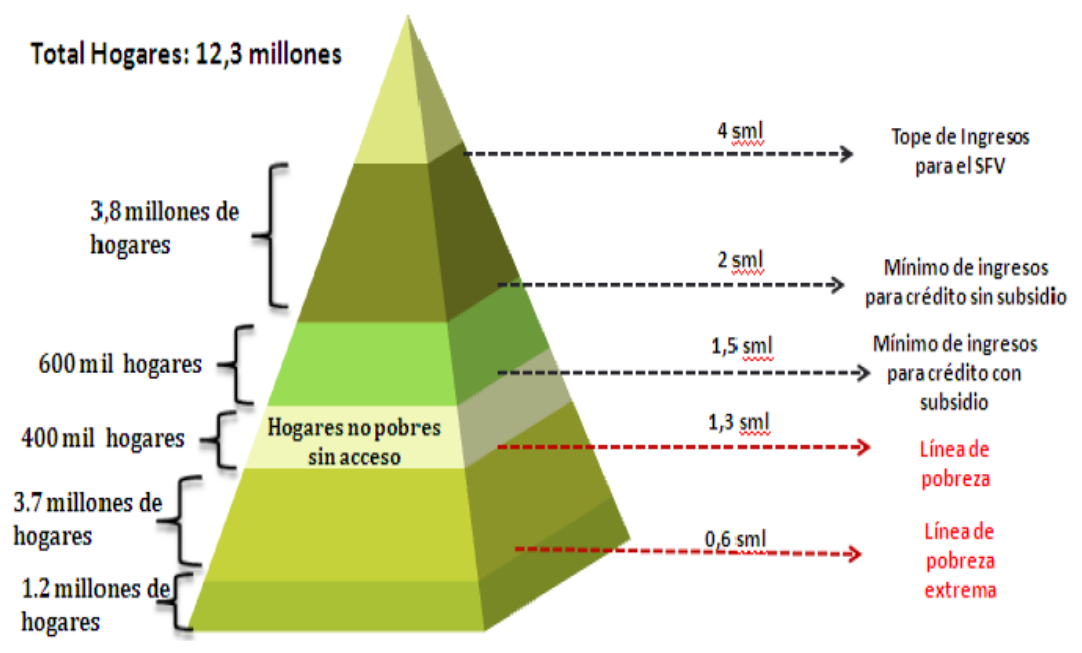

Fuente: DNP, 2013.

Según el Censo del 2005, el déficit total de Vivienda en el país asciende a 3 828055 viviendas, del cual corresponde a un déficit cuantitativo 1307 757, y a un déficit cualitativo 2520298 viviendas; déficit que se registra principalmente en los hogares ubicados en las franjas de hogares no pobres sin acceso, y en aquellos que se encuentran por debajo de la línea de pobreza, sin la posibilidad de acceder al sistema de créditos hipotecarios.

Como estrategia para ampliar la oferta del crédito hipotecario a las familias de escasos recursos, se ha previsto la figura del micro-crédito inmobiliario para núcleos con ingresos no superiores a $\$ 606000$ mensuales -y que paguen un arriendo de $\$ 114$ 000 aproximadamente-, reconociéndoles créditos de hasta 10 millones de pesos a largo plazo, y con garantía parcial de hasta 70\% por el Fosiga, según se previó en el artículo 97 del Plan Nacional de Desarrollo: "Hacia un Estado Comunitario", del presidente Álvaro Uribe Vélez.

Así mismo, como estrategia financiera para la dinamización de la demanda en el sector de la vivienda de interés social, se ha implementado el subsidio a las tasas de interés de créditos hipotecarios otorgados por entidades financieras del Sistema Nacional con cargo al Fondo de Reserva para la Estabilización de la Cartera Hipotecaria del Banco de la República-FRECH-; instrumento financiero previsto en el artículo 123 de la Ley 1450 de 2011, que le ha permitido a los usuarios del sistema acceder a créditos hipotecarios con tasas de interés por debajo del promedio ofrecido por el sistema financiero, en las condiciones normales del mercado. Según cifras gubernamentales, gracias a este instrumento: 
Desde el inicio del programa en abril de 2009, se inscribieron entre 3000 y 5000 créditos nuevos por mes, a excepción de diciembre de 2011, donde se presentaron 1548 inscripciones, debido al agotamiento de los cupos para los rangos 2, 3 y 4 . De esta forma, se inscribieron en promedio 4064 créditos mensuales. Con fecha de corte 10 de febrero de 2012, se desembolsaron 136 132 créditos con cobertura condicionada por valor de 5.4 billones de pesos para una inversión total en vivienda de \$ 9.5 billones. El 69\% del total de créditos se otorgó al segmento de Vivienda de Interés Social (VIS), lo cual evidencia el interés del Gobierno Nacional en darle prioridad a los hogares de menores ingresos (Compes, 2012, p. 9).

Pese a la reactivación de indicadores como el índice de otorgamiento de licencias, créditos otorgados, las iniciaciones, desembolsos de créditos hipotecarios y al clima favorable que se respira en el sector de la construcción de vivienda en los últimos años gracias en buena medida al instrumento del subsidio a las tasas de interés; son también conocidas sus limitaciones e insuficiencia respecto de la gran problemática de inaccesibilidad de la población pobre a los recursos financieros fundamentales para la adquisición de vivienda y la materialización del derecho constitucional.

Debido a que la política de vivienda del subsidio a la demanda -como extensión del modelo de desarrollo social del liberalismo económico y del mercado- ha resultado insuficiente en el propósito de consolidar un sistema de financiación incluyente que represente las condiciones socioeconómicas objetivas del grueso de la población colombiana, y en especial de aquella que vive en medio de la informalidad, el desplazamiento y la pobreza multidimensional, entre otras, ha resultado necesario el que el Estado colombiano intervenga en el sector con la implementación de una estrategia de alto impacto social como lo es el "Programa de Vivienda Gratis" del actual presidente Juan Manuel Santos, el cual se encuentra focalizado en Población del Sisben 1 y 2, Tercera Edad, Población Desplazada, Madres Cabeza de Hogar y Familias en condiciones de Pobreza Extrema.

Esta iniciativa del Gobierno del actual presidente Santos ha dado lugar a la expedición de la Ley 1537 del 2012, mediante la cual se dictan normas tendientes a promover el desarrollo urbano y el acceso a la vivienda de interés social (VS) ${ }^{22}$ e interés prioritario (VIP), trayendo consigo importantes ajustes al Sistema Nacional de Vivienda.

22 Decreto 2190 de 2009, Reglamentario de la Ley 9 de 1989, Ley 3 de 1991, Ley 388 de 1997 y Ley 1151 de 2007, dentro del acápite de definiciones, establece qué es "Vivienda de Interés Social y Vivienda de Interés Social Prioritario": artículo $2^{\circ}$ Definiciones. Para los efectos del presente Decreto se adoptan las siguientes definiciones: 2.1 Vivienda de Interés Social (VIS) es aquella que reúne los elementos que aseguran su habitabilidad, estándares de calidad en diseño urbanístico, arquitectónico y de construcción, cuyo valor máximo es de ciento treinta y cinco salarios mínimos legales mensuales vigentes (135 smlm). 2.2: Vivienda de Interés Social Prioritaria (VIP) es aquella vivienda de interés social cuyo valor máximo es de setenta salarios mínimos legales mensuales vigentes $(70 \mathrm{smlm})$. 
Dentro de los ajustes más significativos en procura de reducir los déficit cuantitativos y cualitativos en la vivienda de interés social y prioritaria, se destacan: i) Designación de un porcentaje del $20 \%$ del presupuesto nacional para los municipios de categorías 4,5 y 6 , según los criterios de distribución reglamentados por el Ministerio de Vivienda. ii) Adopción del modelo jurídico y financiero del patrimonio autónomo y la fiducia mercantil para la cofinanciación, administración e inversión de los recursos provenientes de la nación, de los entes territoriales, de los subsidios de vivienda y de los aportes que las familias beneficiarias hagan a título de ahorro programado o aportes provenientes de los créditos otorgados por entidades financieras, y de los aportes invertidos por organismos de cooperación internacional u ONG, todos estos con destino al desarrollo de proyectos específicos de vivienda prioritaria. iii) Un cambio sustancial del régimen legal en lo referente a la administración y contratación para la ejecución de los proyectos de VIP, que en virtud de la creación de los patrimonios autónomos se sustraen del ámbito del derecho administrativo público al régimen privado, ofreciendo mayor flexibilidad y agilidad en su desarrollo. iv) Priorización de los recursos de inversión provenientes del sector salud, medio ambiente, saneamiento básico, tecnologías de la información y desarrollo urbano de todos los niveles administrativos, para la generación de condiciones de calidad de vida de la población beneficiaria en los proyectos de vivienda prioritaria, ejecutados a través del modelo de patrimonio autónomo. iv) Establecimiento de estrategias para fomentar la construcción de vivienda prioritaria y de interés social en el sector rural a través del Banco Agrario, estableciendo como fórmula para la distribución de los recursos del subsidio rural los porcentajes del déficit cuantitativo y cualitativo que reporte el DANE en cada región. v) Se faculta al Findeter para la suscripción de empréstitos nacionales o internacionales con destino a financiar vivienda prioritaria. vi) Importantes medidas en materia de disponibilidad del suelo urbanizable, como los inventarios de inmuebles públicos o privados potencialmente urbanizables a cargo de alcaldes y gobernadores; la incorporación en los planes parciales de expansión urbana de un 20\% como mínimo sobre el total del área residencial para VIP, y facultad transitoria a los alcaldes para la incorporación del suelo rural, suburbano y de expansión urbana al perímetro urbano para el desarrollo de VIP, entre otras disposiciones.

\section{Los modelos asociativos de gestión en el marco del Sistema Nacional de Vivienda}

Como se ha expuesto, el derecho social a la vivienda previsto en el artículo 51 de nuestra Constitución se erige en una política púbica tridimensional compuesta por: "La promoción de proyectos de vivienda de interés social, el flujo de recursos financieros provenientes del crédito hipotecario de vivienda y el fomento a los modelos asociativos de ejecución o gestión de vivienda", lo cual, representa un mandato constitucional que obliga y vincula a las tres ramas del poder público del Estado en procura de realizar este derecho de carácter social. 
El Legislativo, mediante la expedición de la Ley 3 de 1991 (SNV), desarrolla la disposición constitucional del artículo 51 al diseñar un sistema nacional de vivienda a partir de tres subsistemas denominados: "de fomento o ejecución; de asistencia técnica y promoción de la organización social, y de financiamiento"; con los cuales se persigue la confluencia articulada de las institucionales sectoriales, los entes territoriales, la sociedad civil, la banca privada, las empresas de la construcción y la participación de los beneficiarios del subsidio en procura de lograr los objetivos que persigue la política pública de vivienda.

Las OPV no solo son reconocidas por el Sistema Nacional, adicionalmente terminan ocupando un espacio importante en el subsistema de fomento y ejecución y en el subsistema de asistencia técnica y promoción a la organización social en el marco de los cuales participan e interactúan con los organismos de carácter público y privado que los componen evaluando, analizando, promoviendo y recomendando acciones tendientes a mejorar la producción de vivienda social conforme lo estipula el artículo 2 de la Ley 3 de 1991.

Ahora bien, es fundamental discernir si el reconocimiento nominal que las OPV y los Modelos Asociativos de Gestión de Vivienda reciben en virtud del Decreto 2391 de 1986 y de la Ley 3 de 1991 constituyen, per se, una política idónea para el desarrollo material del mandato constitucional de promover los modelos asociativos de gestión de vivienda de interés social que demanda nuestra Constitución Política.

$\mathrm{Si}$ bien es cierto, en el SNV confluyen actores con funciones integradoras, de asistencia técnica, de control y de financiamiento que desde el nivel nacional, departamental o municipal pueden incidir en el enfoque de la política pública, es claro, el que la esencia misma del modelo de mercado que encarna la Ley 3 de 1991 convierte al subsidio, al sistema financiero y a la empresa de la construcción en sus pilares estructurales llevándose la atención gubernamental que, como se ha descrito, se empeña en disminuir las tasas del interés hipotecario, en ampliar la cobertura del subsidio familiar de vivienda, en ofertar líneas alternas de micro crédito para la población marginada y, en el mejor de los casos, en la aplicación de instrumentos de gestión urbana para promover la Vivienda de Interés Social y Prioritaria.

Según las disposiciones de la Ley 3 de 1991 y de la Ley 1537 del 2012 las OPV son parte en las instancias de asistencia técnica y fomento a la organización social, o son potenciales beneficiarias de subsidios colectivos de vivienda o pueden ser parte en los patrimonios autónomos constituidos para el desarrollo de proyectos de Vivienda de Interés Social, sin que sea claro cómo, a partir de este reconocimiento, son promovidos los modelos asociativos de vivienda en virtud del mandato constitucional contenido en el artículo 51 ya descrito.

Las OPV son un actor reconocido en el SNV en consonancia con la estrecha relación histórica que el modelo asociativo de vivienda de carácter popular y obrero tiene con el desarrollo habitacional y el perfil urbano de las principales ciudades del país, en este sentido se podría ver como una reivindicación histórica de la autogestión vivienda popular; no obstante su reconocimiento nominal no implica necesariamente 
un auténtico esfuerzo institucional, presupuestal y político para convertirlo en una alternativa de materialización del derecho social a la vivienda.

Con la liquidación del Inurbe se podría decir que desparece la única entidad del nivel nacional que mediante la asistencia técnica y el otorgamiento de créditos se encargaba específicamente de promover a las OPV, quedando esta responsabilidad, actualmente, en cabeza de los Fondos Municipales de Vivienda, según lo previsto en el artículo 18 de la citada Ley 3 de 1991. Igualmente, el Decreto 2391 de 1989 ha favorecido, en cierta medida, su promoción y desarrollo gracias a la regulación de sus condiciones de conformación, organización, operación y de control ofreciendo mejores garantías y confiabilidad a sus usuarios; sin embargo, paradójicamente, dadas las limitantes en recursos, acceso a la información, capacitación y formación jurídica, técnica y gerencial del grueso de la población que decide optar por este modelo de autogestión de vivienda, dichas exigencias legales terminan -en algunas ocasiones-, rompiendo la dinámica del movimiento, desarticulándolo o minando el empeño de sus miembros.

Se colige de lo anterior que la promoción de los modelos asociativos de vivienda recaen hoy en el ámbito municipal ${ }^{23}$ a la espera de desarrollos normativos, administrativos y presupuestales en este nivel; a la espera de la creatividad e iniciativa que le asista a los mandatarios para emprender tal propósito en un ambiente muchas veces dominado por sesgos políticos, por la debilidad institucional, el desconocimiento y la falta de voluntad política obstáculos que dificultan seriamente el proceso de autogestión de vivienda.

El desarrollo de un proyecto de vivienda mediante un modelo asociativo comunitario- apareja un importante esfuerzo económico, técnico, organizativo, personal, familiar y social para sus integrantes, que de no encontrar respuestas en una política pública fundada en estrategias ágiles, asertivas y conducentes, perecerían en su intento; siendo esto inadmisible, en un Sistema Nacional de Vivienda que privilegia el subsidio y el crédito hipotecario al que solo accede un segmento de la población con capacidad de pago del gran universo de familias en condición de pobreza que demandan el acceso a la vivienda digna.

23 Para tener referentes sobre este tipo de iniciativas podemos citar el plan de Vivienda Diga Asociativa (VIDA) desarrollado con el Programa de Gobierno del Periodo 2008-2011, en el Departamento de Boyacá, a partir del cual se fomentó el desarrollo de OPV como estrategia para promover la adquisición de vivienda propia. Asimismo, el Instituto de Vivienda de Medellín (Insvimed) ha incorporado como estrategia de gestión de vivienda el apoyo técnico y jurídico a las OPV con significativos resultados en la generación de vivienda de interés social o prioritaria en la ciudad. Al margen de la iniciativa de algunos entes territoriales, el movimiento asociativo de gestión aún preserva su dinámica propia y hoy en Colombia existen importantes representantes de este sector como la Federación Nacional de Vivienda Popular (Fenavip), la cual, tiene presencia en varios departamentos del país y agrupa a un número importante de OPV; sin embargo, los logros alcanzados en materia de proyectos de VIS o VIP de esta entidad es atribuible al empeño de representantes de la comunidad con formación profesional, a la mediana capacidad económica de sus afiliados y en no pocas ocasiones al liderazgo de algunos ediles, concejales o políticos que apoyan este tipo de soluciones para las comunidades que representan. 
En una sociedad en la que cerca de cinco millones de familias se encuentran en o por debajo de la línea de pobreza -y sin ninguna posibilidad de acceder a la vivienda ofertada en el mercado del sistema nacional-; los modelos asociativos deberían constituir una alternativa seria y de primer orden en la política pública de un Estado social de derecho que procura garantizar el derecho a la vivienda como un bien íntimamente ligado a la dignidad, desarrollo y bienestar del ser humano.

De no transitar del reconocimiento nominal-legal al desarrollo de estrategias que promuevan verdaderamente una política en la que los modelos asociativos sean un vértice estructural de su diseño las posibilidades de reducir la pobreza y la inequidad con las que el Estado social no comulga y la materialización del derecho social a la vivienda, previsto en el artículo 51 de nuestra Constitución Política, no dejarán de ser una utopía o una proclamación ideológica difícil de sostener.

Corresponde al poder ejecutivo en su nivel nacional, departamental y municipal emprender el desarrollo de una política de vivienda tridimensional que combine las bondades de un crédito hipotecario con tasas que reflejen el nivel de vida del grueso de la sociedad; el desarrollo de proyectos de vivienda de interés social atractivos para el sector inmobiliario o de iniciativa estatal; y el fortalecimiento de los modelos asociativos de gestión de vivienda como una alternativa eficaz para reducir el déficit cuantitativo y cualitativo de vivienda en el país.

\section{CONCLUSIONES}

Los modelos asociativos de vivienda han acompañado el desarrollo urbano y habitacional de las principales ciudades del país que debieron soportar la presión demográfica desatada por la industrialización de nuestra economía emprendida a partir de la segunda mitad del siglo XX, dando paso a la conformación de barrios obreros y populares que paulatinamente fueron objeto de intervención estatal, en principio, desde un enfoque higienista y, con los años, a través de un modelo de política institucional-intervencionista liderada por el ICT, el BCH y la Caja Agraria, principalmente.

Con la institucionalización de la acción estatal en las décadas del cuarenta, cincuenta y sesenta se emprende una política intervencionista en el campo de la vivienda de interés social que da paso a la construcción de barrios concebidos con la infraestructura de servicios públicos, vial y de transporte adecuada; se adelanta una estrategia de intervención a barrios subnormales para mejorar sus condiciones urbanas y habitacionales e integrarlos formalmente a las ciudades, y se implementaron estrategias de crédito dirigido a los trabajadores y cooperativas gremiales con el fin de fomentar la autoconstrucción como una estrategia eficiente para dotar de vivienda adecuada a la población rural y urbana.

Para el Constituyente del 1991 los modelos asociativos de vivienda se convierten en un instrumento esencial de la política pública que se encamine a realizar el derecho social a la vivienda digna previsto en el artículo 51 de nuestra Constitución 
Política, trascendiendo esta concepción en el reconocimiento que las OPV reciben en el subsistema de asistencia técnica y fomento a la organización social del Sistema Nacional de Vivienda vigente con la Ley 3 de 1991.

No obstante, existe un reconocimiento legal y reglamentario de las OPV; este no encierra, per se, el deber constitucional de "promover formas asociativas de ejecución de estos programas de vivienda" que demanda nuestra Carta Política y que constituye un mandato imperativo para las ramas del poder público y en especial para el poder ejecutivo en todos sus niveles de descentralización territorial y funcional.

La trayectoria histórica de los modelos asociativos de vivienda y los estrictos términos del artículo 51 de la Constitución Política reclaman un esfuerzo institucional y presupuestal que incentive y fortalezca las iniciativas comunitarias de autogestión de vivienda en un país en el que la economía del mercado y bancarización se convierten en factores de segregación social y económica para un sector de la población que redondea a los cinco millones de familias.

\section{REFERENCIAS}

Álvarez, J. F. (2006). Modelos de cooperativismo en vivienda: una revisión documental. Bogotá. Universidad Cooperativa de Colombia, Instituto de Economía Social y Cooperativismo (Indesco).

Ceballos, O. L., Saldarriaga, A. y Tarchópulos, D. (2008). Vivienda social en Colombia: Una perspectiva desde su legislación. Bogotá: Universidad Javeriana.

Chirivi, E. B., Quiroz, O., Ramírez, S., Rodríguez, D. y Torres, J. (2012). Informe Económico, Estudios Económicos, 38 (pp.1-12). Bogotá: Camacol.

Consejo Nacional de Política Económica y Social (Compes) (2012). Importancia estratégica del Programa de Cobertura Condicionada para Créditos de Vivienda Segunda Generación, No. 3725. Bogotá. Recuperado de www.dnp. gov.com

Departamento Nacional de Planeación (2013). Política Sectorial, Sistema Nacional de Vivienda. Recuperado de http://www.dnp.gov.co/LinkClick.aspx?fileticket $=60$ TSGwpytA\%3d\&tabid $=366$

Departamento Nacional de Planeación (2013). Programas Sectoriales de Vivienda. Recuperado de https://www.dnp.gov.co/Programas/ ViviendaAguayDesarrolloUrbano/Vivienda.aspx

Fique, L. F. (2008). La política pública de vivienda. Conflicto de objetivos. Bogotá: Universidad Nacional de Colombia.

Gaviria, A. (Octubre, 2010). Cambio social en Colombia durante la segunda mitad del siglo XX. CEDE, 30, 44. Revista Electrónica. Bogotá: Universidad de los Andes. Facultad de Economía. Recuperado de http://economia.uniandes.edu.co/ investigaciones_y_publicaciones/CEDE 
Hernández, G. (2006). Diccionario de Economía. Bucaramanga: Universidad Cooperativa.

Ospina, L. (1955). Industria y protección en Colombia (1810-1930). Medellín: Editorial Santa Fe.

Santana, P. (1982). Hacia una política de vivienda popular en Colombia. Seminario la Vivienda Popular hoy en Colombia. Bogotá: Fundación Foro Nacional por Colombia.

Tirado, Á. (1998). Introducción a la historia económica de Colombia. Bogotá: El Áncora Editores.

Urrutia, M. y Namen, O. (2011). Historia del crédito hipotecario de vivienda en Colombia. CEDE. Revista Electrónica. Bogotá: Universidad de los Andes. Recuperado de http://economia.uniandes.edu.co/investigaciones_y_ publicaciones/CEDE

Vélez, E. (2012). Las acciones colectivas y las organizaciones populares en la producción social de vivienda en Medellín a partir de la década de los 90. [Tesis de Maestría en Sociología]. Medellín: Universidad Nacional de Medellín. 